\title{
С .Н. Спорыхина
}

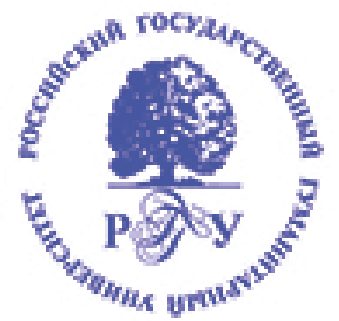

Управленческие

решения:

основные понятия 
С. Н. Спорыхина

\title{
УПРАВЛЕНЧЕСКИЕ РЕШЕНИЯ: ОСНОВНЫЕ ПОНЯТИЯ
}

\author{
Учебное пособие
}

Чебоксары

Издательский дом «Среда»

2022 


\author{
Рецензенты: \\ д-р экон. наук, профессор кафедры «Менеджмент и экономика» \\ Новошахтинского филиала \\ ФГАОУ ВО «Южный федеральный университет» \\ Радина Оксана Ивановна; \\ канд. экон. наук, член-корреспондент РАЕН, \\ приглашенный преподаватель и член ГЭК \\ ФГБОУ ВО «Российский экономический \\ университет им. Г.В. Плеханова» \\ Машин Дмитрий Васильевич
}

\title{
Спорыхина С. H.
}

С73 Управленческие решения: основные понятия : учеб. пособ. / С. Н. Спорыхина. - Чебоксары: ИД «Среда», 2022. -92 c.

\section{ISBN 978-5-907561-02-1}

Пособие адресовано студентам всех форм обучения по направлению подготовки «Менеджмент» и «Экономика». Курс «Управленческие решения» является одним из базовых в целях подготовки кадров управленческой направленности, поскольку принятие решения является основной и важнейшей частью управленческой деятельности. Компетентность руководителя в первую очередь определяется эффективностью управленческих решений, принимаемых им.

Основная цель пособия - помочь студентам, изучающим курс «Управленческие решения», научно осмыслить теоретические основы и приобрести практические навыки по вопросам процесса принятия управленческих решений.

ISBN 978-5-907561-02-1

DOI 10.31483/a-10359
(C) Спорыхина С. Н., 2022

(c) ИД «Среда», оформление, 2022 


\section{Оглавление}

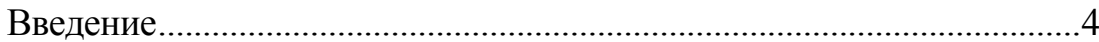

Глава 1. Теоретические основы разработки управленческих решений .................................................................................. 5

Глава 2. Типовая схема процесса разработки, принятия, реализации управленческого решения....................................................................19

Глава 3. Разработка управленческого решения в условиях неопределенности и риска ......................................................................27

Глава 4. Методы принятия управленческих решений ..........................40

Глава 5. Качество принимаемого управленческого решения .............50

Глава 6. Контроль реализации управленческих решений ...................62

Глава 7. Инструменты и характеристики эффективного контроля реализации управленческих решений ......................................................82

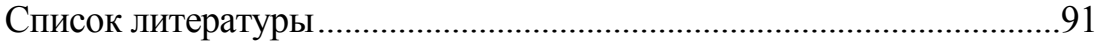




\section{Введение}

Пособие адресовано студентам всех форм обучения по направлению подготовки «Менеджмент» и «Экономика». Курс «Управленческие решения» является одним из базовых в целях подготовки кадров управленческой направленности, поскольку принятие решения является основной и важнейшей частью управленческой деятельности. Компетентность руководителя в первую очередь определяется эффективностью управленческих решений, принимаемых им.

Основная цель пособия - помочь студентам, изучающим курс «Управленческие решения» научно осмыслить теоретические основы и приобрести практические навыки по вопросам процесса принятия управленческих решений.

Материалы пособия предназначены к использованию как на семинарских занятиях, так и для внеаудиторной работы студентов. Пособие содержит тесовые задания по темам, рассмотренным в нем. Для студентов заочной и очно-заочной форм обучения тесовые задания могут служить в качестве контрольной работы. Тестовые задания направлены на проверку знаний общих, принципиальных положений дисциплины, определенных конечным результатом и, в конечном счете, целями изучения дисциплины. Работа с данным пособием позволит сформировать и закрепить навыки системного мышления и умение самостоятельного приобретения знаний. 


\section{ГЛАВа 1. ТЕОРЕТИЧЕСКИЕ ОСНОВЫ РАЗРАБОТКИ УПРАВЛЕНЧЕСКИХ РЕШЕНИЙ}

Принятие управленческого решения является неотъемлемой составляющей процессов управления. Управленческое решение через такие характеристики как качество, эффективность определяют возможность устойчивого планомерного развития управляемой системы в условиях ускорения всех процессов и быстрых изменений, характерных для современного мира.

Не все решения, принимаемые лицом, принимающим решения (как правило, это руководитель организации), являются управленческими. Управленческим считается решение, которое принято в социальной системе. Управленческим является решение, принятое в области кадров, проектирования системы управления, стратегического планирования, управленческого консультирования, взаимодействия с внешней средой.

В теории принятия решений рассматриваются расширенное и узкое определение понятия «управленческое решение». Узкое сводит принятие решений к выбору наилучшей из альтернатив. Широкое - трактует его как процесс, имеющий свои закономерности, этапы и задачи. Управленческое решение как процесс является содержанием планирования, организации, мотивации и контроля функций управления. Также при определении содержания понятия «управленческое решение» акцентируют внимание на разнообразных аспектах деятельности лица, принимающего решение. Тогда содержание понятия сводят к действию, обладающему волевыми и творческими характеристиками, основанному на профессиональных знаниях в области управления, анализе информации о функционировании управляемой системы, и заключающемся в выборе цели, разработке плана действия, выработке способов разрешения проблемы.

Таким образом, управленческое решение это и процесс, и явление. Как процесс - это поиск, переработка и анализ информации, разработка альтернатив, выбор лучшей из них, утверждение и реализация. Как явление управленческое решение - это план действий, приказ, программа, постановление устное или письменное распоряжение. 
Масштаб воздействия управленческого решения может быть распространён на одного человека, подразделение организации или всю организацию. Любое управленческое решение имеет целевую природу, целевую направленность. Прогноз возможных результатов реализации управленческого решения может быть выполнен с достаточной точностью, либо с вероятностным исходом. Существует множество причин, по которым результаты реализации управленческого решения могут не совпасть с запланированными. Существует зависимость характера разработки и реализации управленческого решения от личностных качеств руководителяразработчика управленческого решения.

Управленческим решением называют творческое, волевое действие субъекта управления, основанное на знании объективных законов функционирования управляемой системой и анализе информации о ее функционировании, состоящее в выборе цели, программы и способов разрешения проблемы. Управленческое решение является основой процесса управления. Управлять - значит решать.

Сущность управленческого решения связана с социальными экономическими, организационными, правовыми, технологическими аспектами деятельности организации.

Социальный аспект проистекает из соотнесенности любого управленческого решения с персоналом организации. При принятии управленческого решения необходимо учитывать необходимость воздействия на персонал организации с целью достижения цели, согласованности действий и взаимодействий между персоналом организации. Социальная сущность управленческого решения проявляется и в том, что любое управленческое решение должно не противоречить необходимости создания комфортной среды для работы персонала, нацелено на развитие системы участия в управлении, всестороннее развитие личности, учета индивидуальных предпочтения. Экономическая сущность управленческого решения связана с тем, что для его разработки, принятия, реализации необходимы финансовые, материальные, временные, человеческие ресурсы. Следовательно, любое управленческое решение имеет свою стоимость. Организационная сущность управленческого решения обусловлена тем, что для обеспечения эффективной работы организации необходимо осуществить комплекс мер, направленных на 
формирование работоспособного коллектива: разработать должностные инструкции и положения, наделить сотрудников полномочиями, правами, обязанностями и ответственностью, обеспечить систему контроля, предоставить необходимые ресурсы и технические средства, координировать работу. Управленческое решение его подготовка и реализация должно соответствовать действующему законодательству. В этом состоит правовая сущность управленческого решения. Технологическая сущность управленческого решения связана с необходимостью обеспечения работников техническими и информационно-коммуникационными ресурсами без которых невозможно разработать эффективное управленческое решение и его реализовать.

Управленческие решения фиксируются в распорядительных актах - формах разработки. К ним относятся указ, закон, приказ, распоряжение, указание, акт, акцепт, протокол, инструкция, договор, соглашение, план, контракт, оферта, положение, правила, модель.

Указ - это решение главы государства, утвержденное парламентом. Например, Указ Президента РФ, утверждённый Думой РФ. Указ имеет силу закона.

Закон - решение высшей государственной власти, носящее обязательный и непреложный характер. Приказ - решение, принимаемое руководителем органа государственного или муниципального управления, действующего на основе единоначалия, в целях решения основных и оперативных задач, стоящих перед данным органом. В некоторых случаях приказ может касаться широкого круга организаций и должностных лиц независимо от подчиненности. Распоряжение - решение руководителя, принимаемое в целях разрешения оперативных вопросов. Указание - решение, разрабатываемое органом государственного управления по вопросам информационно-методического характера, а также по вопросам, связанным с организацией исполнения приказов, инструкций и других актов данного органа и вышестоящих органов управления, носящее методический, технологический характер. Акт - решение широкого круга государственных и общественных организаций, подтверждающее установленные факты, события, действия. Акцепт решение о приеме предложения о заключении сделки на предложенных в оферте условиях. Акцепт - это вторая сторона контракта, 
оферта и акцепт составляют контракт. Протокол - решение, принимаемое коллегиальным органом или группой лиц, но вопросам, требующим совместного обсуждения. Инструкция - решение, устанавливающее порядок и правила выполнения каких-либо действий в определенной сфере деятельности. Договор - решение двух и более сторон об установлении, изменении и прекращении правоотношений. Соглашение - решение, формирующее общую позитивную инфраструктуру для какой-либо деятельности. План - peшение, отражающее цели и конкретные задачи деятельности, средства, методы и время их реализации. Контракт - решение коммерческого характера о выполнении совместной деятельности с указанием взаимных прав и обязательств. Оферта - решение, обычно коммерческого характера, о предложении конкретному (любому) лицу заключить сделку на указанных условиях Оферта является одной стороной контракта. Положение - решение, представляющее собой набор законов, правил и инструкций, регламентирующих определенный вид деятельности. Правила - решение, представляющее набор предлагаемых для исполнения устоявшихся норм поведения и деятельности определенных групп работников. Модель решение, включающее набор определенных элементов и связей, который с заданной точностью воспроизводит реакции реального процесса или явления на внешние воздействия

К формам реализации управленческих решения относят: деловую беседу, предписание, убеждение, разъяснение, принуждение, наставление, сообщение, личный стример, обучение, совет, деловые игры, совещания, заседания, отчет, деловое слово.

Деловая беседа - встреча руководителя с подчиненным для обсуждения заранее оговоренной темы. Предписание - официальное извещение, направленное конкретному исполнителю, об обязательном выполнении решения в установленный срок. Убеждение деловая беседа, проводимая руководителем с целью добиться у подчиненного требуемых прочных взглядов или понятий по содержанию управленческого решения для его выполнения. Разъяснение - деловая беседа, проводимая руководителем с целью объяснить, сделать более понятным суть и содержание управленческого решения. Принуждение - деловая беседа, проводимая руководителем с целью осознанно заставить работника выполнить управленческое решение путем угроз или повышенного вознаграждения. 
Наставление - деловая беседа, проводимая руководителем с целью научить, передать опыт для успешного выполнения управленческого решения. Сообщение - деловая беседа, проводимая для выполнения руководителем с целью передачи дополнительной информации, необходимой для выполнения управленческого решения. Личный пример - действия руководителя в среде подчиненных по заранее подготовленному сценарию для развития у них эффекта подражания авторитетам в технике выполнения управленческого решения. Обучение - деловая беседа, проводимая руководителем для выполнения с целью дать новые знания или информацию по управленческому решению. Совет - деловая беседа, проводимая руководителем с целью поделиться собственными взглядами на пути выполнения УР. Совет не является обязательным для исполнения подчиненным. Деловая игра (тренинг) - специально организованная интенсивная деятельность работников по разработке и реализации управленческих решений на основе имитационных моделей реальных процессов. Совещания - коллективные деловые беседы, проводимые руководителем с целью оперативного доведения до подчиненных конкретных задач, использования коллективного разума, обмена информацией и накопленным опытом для выполнения важных управленческих решений. Заседания - узко профессиональные совещания для решения в основном организационных вопросов (например, заседание профкома, заседание президиума и т.д.). Отчет - решение специалиста о результатах индивидуальной или коллективной проделанной работы по выполнению управленческих решений. Отчет может быть письменным и устным. Деловое слово - твердое решение руководителя, данное подчиненному в устной форме, подкрепленное авторитетом руководителя как среди подчиненных, так и среди вышестоящего руководства. Каждой форме разработки управленческого решения соответствует несколько форм реализации.

Классифицировать - значит отнести управленческое решение к определенному виду или типу. Классифицировать решения необходимо, поскольку каждый тип управленческого решения имеет свои правила разработки, принятия и реализации. Также правильное отнесение управленческого решение к какому-то виду или типу позволит сократить время на все необходимые процедуры принятия управленческого решения и, в конечном счете, определит его 
эффективность и обоснованность. Процесс отнесения управленческого решения к виду или типу заключается в последовательных ответах на ряд вопросов: в какие сроки необходимо принять решение; к чьим полномочиям относится принятие управленческого решения; каких специалистов необходимо привлечь для принятия решения; кто будет утверждать решение. Существуют разнообразные классификации управленческих решений. Это обусловлено тем, что условия принятия решения для современной организации характеризуются сложностью, многообразием факторов, влияющих на ситуацию, определяются целями принятия решения, требованиями, предъявляемыми к управленческим решениям.

По признаку классификации «функциональная направленность» решения подразделяют на: планирующие, организующие, активизирующие, координирующие, контролирующие, информирующие. Планирующие управленческие решения принимают для осуществления плановых мероприятий. Решение организационных проблем возможно при принятии организационных решений. Необходимость согласования изменяющихся условий внешней и внутренней среды организации вызывает принятие координирующих решений. Обеспечение своевременного выполнения намеченных мероприятий и контроля выполнения является условием принятия контролирующего управленческого решения. Для предоставления сотрудникам необходимой информации разрабатываются информирующие решения.

По признаку «причины принятия управленческого решения» выделяют: ситуационные решения - данные управленческие решения обусловлены событиями, которые произошли вне плана. Эти решения несут текущий характер; по предписанию - данные решения принимаются в рамках действующих регламентов на предприятии; программные - это долговременные решения, которые являются основой для детальных решений; инициативные - инициативные решения принимаются руководителем организации или руководителем среднего звена.

По признаку «время воздействия на объект управления» выделяют: оперативные - данные управленческие решения разрабатываются и принимаются в случае возникновения ситуаций, которые мешают реализации тактических решения, имеют кратковремен- 
ный характер; тактические - они разрабатываются с целью реализации стратегических решений на период 1-3 года; стратегические - этот вид управленческого решения принимаются на длительный срок от 5 до 10 лет.

По признаку «организация принятия решения» выделяют: индивидуальные - они принимаются лицом, уполномоченным принимать решения, которое должно обладать высоким статусом в организационной иерархии, несущем персональную ответственность за результаты реализации управленческого решения; коллективные принимаются на основе голосования или консенсуса членами коллектива; коллегиальные - при коллегиальной форме принятия решения работу по подготовке и принятию решения выполняет группа уполномоченных коллективом специалистов.

По признаку классификации «способ фиксации управленческие решения» выделяют: письменные - письменное управленческое решение предполагает, что фиксация решения осуществляется в письменном виде; устные; устные управленческие решения - они предполагают вербальные коммуникации между участниками управленческого процесса. У устной формы управленческого решения есть существенный недостаток, заключающийся в том, что исполнители могут исказить содержание, причем не, всегда осознанно, и трактуют решение по-своему; электронные - данный способ предполагает фиксацию решений на электронных носителях информации.

По признаку классификации «степень новизны» решения делятся на: традиционные. При принятии традиционного решения используют известный и апробированный алгоритм. Этот вид решения принимается в основном на среднем и нижнем уровне организационной структуры; оригинальные. Для решения новых проблем принимаются оригинальные решения.

По признаку классификации «содержание решения» выделяют: решения, имеющие количественные характеристики. Решения, имеющие количественные характеристики, например, утверждение бюджета, привлечение инвестиций, принимаются на основе математических и статистических методов; решения, не имеющие количественных характеристик. Решения, которые не имеют количественных характеристик, таких, например, как формирование 
корпоративной культуры, кадровые вопросы, управление организационными отношениями, носят субъективный характер, так как определяются личностью субъекта, их принимающего.

В зависимости от степени регламентации различают решения: директивные (нормативные). Нормативные решения обязательны к исполнению и не предполагают никакой инициативы, устанавливают четкую взаимосвязь между параметрами и конкретными вариантами решения; ориентирующие. Ориентирующие решения определяют возможные варианты деятельности сотрудников при наступлении определенных условий; рекомендующие. Рекомендующие решения определяют возможные направления деятельности сотрудников, не предоставляя им конкретной схемы действий.

Классификация в зависимости от системы оценки эффективности (числа критериев) подразделяет решения: однокритериальные. Однокритериальные решения позволяют оценивать альтернативы на основе одного критерия (показателя), степень важности которого может зависеть от объективных условий или определяться субъективно лицом, принимающем решения; многокритериальные. При оценке многокритериальных решений используется система показателей. Это создает дополнительные трудности, так как необходимо выбрать показатели и оценить их влияние на конечный результат.

В зависимости от способа выработки различают следующие типы решений: интуитивные. Интуитивные решения принимают на основе ощущения того, что они верны. Руководитель не занимается оценкой всех плюсов и минусов каждого варианта, а просто делает выбор; рациональные. Рациональный способ решения проблем называют лучшим. Он предполагает формулирование всех возможных альтернатив, разработку системы критериев их оценки и выбор на основе этой системы предпочтительного варианта; основанные па суждениях. Решения, основанные на суждениях, принимаются на базе знаний и накопленного опыта. Они основываются на прогнозе будущих результатов. Метод гарантирует недопущение грубых ошибок.

Принято различать уравновешенные, импульсивные, инертные, рискованные, осторожные решения. Принятие уравновешенных решений характерно для менеджеров, которые внимательно, кри- 
тически относятся к своим действиям по прогнозированию, формулированию проблемы, выдвижению гипотез и их проверке. Импульсивные решения принимают менеджеры, которые легко генерируют множество идей, но не способны к их проверке, уточнению и оценке. Инертные решения принимаются руководителем, который в процессе принятия решения больше времени уделяет контрольным, уточняющим действиям, чем этапу генерации идеей. Такие решения характеризуются отсутствием оригинальности и новаторства. Рискованные решения принимаются уверенным в своих силах менеджером, без тщательного обоснования действий. Руководители, склонные к принятию решений осторожного типа очень критично оценивают каждый шаг, прибегают к значительному количеству согласований.

\section{Контрольные вопросы.}

1. Почему необходимо классифицировать управленческие решения?

2. Какие принципы классификации управленческих решений существуют?

3. Какие определения понятия «управленческое решение» существуют?

4. В чем заключается сущность управленческого решения как процесса и как явления?

5. Какие существуют формы реализации и разработки управленческих решений?

\section{Контрольные тесты.}

1. Лицо, наделенное правом принимать решения или их реализовывать, называется:

1) субъектом решения;

2) директор;

3) ответственное лицо;

4) управляющий.

2. Тех, кто оценивает решения, называют:

1) консультантами;

2) экспертами;

3) специалистами;

4) инструкторами. 
3. Решение может приниматься человеком в системах:

1) технической;

2) культурнои;;

3) социиальной;

4) организационной.

4. Решения, принимаемые руководителем в социальной системе, называются:

1) целевыми;

2) организачионнымия;

3) управленческими;

4) сочииальными.

5. Организационная сущность управленческого решения состоит в том, что организация должна иметь:

1) систему контроля;

2) необходимый персонал;

3) возможность оперативного перераспределения ресурсов;

4) утвержденный план.

6. Социальная сущность управленческого решения заключается в:

1) механизме адаптации существующей организационной структуры управления под новые цели и задачи;

2) механизме управления исполнителями с иелью достижения взаимодействия всех его участников;

3) координации и регулировании управляемьх объектов;

4) технологиях сбора информации о деятельности объекта

7. Технологическая сущность управленческого решения заключается в:

1) стимулировании эффективного труда руководителей организации;

2) стимулировании труда сотрудников организации;

3) возможности обеспечения персонала необходимыми техническими, информационными средствами и ресурсами;

4) возможности обеспечения эффективной работы организации по реализации управленческого решения.

8. Управленческое решение - это:

1) прочесс;

2) $a \kappa m$;

3) факт;

4) организационный момент. 
9. К формам разработки управленческого решения относят:

1) указ;

2) положение;

3) устав;

4) схема.

10. К формам реализации управленческих решений относят:

1) соглашение;

2) договор;

3) сообщение;

4) совет.

11. Оферта и акцепт составляют:

1) контракт;

2) договор;

3) положение;

4) модель.

12. По признаку управленческих функций решения подразделяют на:

1) решения по планированию;

2) индивидуальные решения;

3) решения по маркетингу;

4) организационное решение.

13. По объекту управления выделяют:

1) решения по производству;

2) групповые решения;

3) единичные решения;

4) решения мотиваџии участников организации.

14. Синергетические решения - это решения, при которых эффективность расходования ресурсов на единицу полученного эффекта:

1) непропоричионально снижается;

2) соответствует нормам и нормативам;

3) резко возрастает;

4) резко возрастает, а затем снижается.

15. Экономические решения классифицируют на:

1) финансовые;

2) оперативные;

3) стабилизационные;

4) стратегические. 
16. По времени наступления последствий для объекта управления и среды решения могут быть:

1) среднесрочные;

2) долгосрочные;

3) стратегические;

4) разовые.

17. По содержанию управленческие решения классифицируют на:

1) экономические;

2) политические;

3) инновационнье;

4) юридические.

18. По степени охвата и регулирования общественных отношений управленческие решения делятся на:

1) единичныле;

2) социильные;

3) всеобщие;

4) раздельные.

19. По форме управленческие решения подразделяют на:

1) письменные;

2) договорныле;

3) приказ;

4) указание.

20. В зависимости от порядка разработки и принятия, управленческие решения, подразделяют на:

1) индивидуальные;

2) непосредственные;

3) единоличные;

4) опосредованные.

21. В зависимости от того, на какой стации управленческого процесса возникают управленческие решения их можно классифицировать на:

1) регулятивные;

2) контрольныле;

3) координирующие;

4) эффективные. 
22. Обоснованные управленческие решения, приводящие к достижению поставленной цели, принятые на основании глубокой проработки имеющейся информации называются:

1) уравновешенные;

2) импульсивные;

3) инертные;

4) осторожные.

23. Лицо, наделенное правом принимать решения или их реализовывать, называется:

1) субъектом решения;

2) директор;

3) ответственное лиия;

4) управляющий.

24. Тех, кто оценивает решения, называют:

1) консультантами;

2) экспертами;

3) специалистами;

4) инструкторами.

25. Решение может приниматься человеком в системах:

1) технической;

2) культурной;

3) сочиальной;

4) организационной.

26. Решения, принимаемые руководителем в социальной системе, называются:

1) изелевыми;

2) организационными;

3) управленческими;

4) сочиальными.

27. Организационная сущность управленческого решения состоит в том, что организация должна иметь:

1) систему контроля;

2) необходимый персонал;

3) возможность оперативного перераспределения ресурсов;

4) утвержденный план. 
28. Социальная сущность управленческого решения заключается в:

1) механизме адаптациии существующей организационной структуры управления под новые цели и задачи;

2) механизме управления исполнителями с целью достижения взаимодействия всех его участников;

3) координации и регулировании управляемых объектов;

4) технологиях сбора информации о деятельности объекта

29. Технологическая сущность управленческого решения заключается в:

1) стимулировании эффективного труда руководителей организачии;

2) стимулировании труда сотрудников организащии;

3) возможности обеспечения персонала необходимьми техническими, информационными средствами и ресурсами;

4) возможности обеспечения эффективной работы организации по реализации управленческого решения.

30. Управленческое решение - это:

1) прочесс;

2) $а \mathrm{~km}$;

3) факт;

4) организационный момент. 


\section{ГЛава 2. ТИПОВАЯ СХЕМА ПРОЦЕССА РАЗРАБОТКИ, ПРИНЯТИЯ, РЕАЛИЗАЦИИ УПРАВЛЕНЧЕСКОГО РЕШЕНИЯ}

Принятие управленческого решения является важнейшей составляющей процесса управления в организации. Главное для руководителя разрешение возникшей управленческой проблемы. Для этого необходима последовательность решений и их осуществление. Управленческое решение здесь мы рассматриваем не как одномерный шаг, а как процесс. Процесс принятия решений - это циклическая последовательность действий субъекта управления, направленных на разрешение проблем организации и заключающихся в анализе ситуации, генерации альтернатив, принятии решения и организации его выполнения.

В каждой организации существуют особенности этого процесса, определенные характером и спецификой деятельности, системой ценностей и коммуникаций, организационной культурой. Однако для любого процесса принятия управленческого решения можно выделить основные этапы и последовательность их выполнения.

Типовая схема процесса разработки, принятия, реализации управленческого решения или процесса принятия управленческого решения включает несколько блоков, которые в свою очередь разбиваются на отдельные элементы. Укрупненные блоки процесса принятия управленческого решения: диагностика проблемы; формулировка ограничений и критериев для принятия решения; определение альтернатив; оценка альтернатив; окончательный выбор; реализация решений; обратная связь. Рассмотрим содержание каждого из блоков, этапов и операций процесса разработки, принятия и реализации управленческого решения.

Блок: диагностика проблемы. Включает в себя два этапа: выявление наличия проблемы и структурирование проблемы.

Прежде чем подробно рассматривать содержание данного блока необходимо рассмотреть сущность используемых понятий таких, как проблемная ситуация и проблема. Проблемная ситуация - это некая жалоба на то, что определенные процессы в организации протекают не так, как было запланировано. Индикатором ее наличия обычно служат промежуточные показатели (контрольные точки), характеризующие соответствие осуществляемого процесса норме. 
Любое отклонение от запланированных показателей является проблемной ситуацией, которая требует пристального внимания руководителя, но при этом не является проблемой. Для того чтобы определить принципиальное отличие проблемной ситуации от проблемы, необходимо четко понимать, что в основе любого события лежат как причина, так и следствие. Проблемная ситуация всегда является следствием. Таким образом, проблемная ситуация - это некое препятствие, возникающее при выполнении деятельности, направленной на достижение цели. При этом проблема является причиной возникновения данной ситуации. Практика показывает, что к наиболее часто встречаемым в организации проблемным ситуациям можно отнести: несоответствие фактических показателей плановым показателям, ведущее к неустойчивости и понижающее эффективность деятельности организации; изменение внешних условий функционирования организации; изменение целей организации, обусловленное ее развитием; наличие сигнала за счет существования обратной связи от управляемой подсистемы, сигнализирующая об нежелательных изменениях в системе или стагнации. Рассмотрим этапы первого блока процесса принятия управленческого решения:

- выявление наличия проблемы, структурирование проблемы. На этапе поиска и выявления причин возникновения проблемной ситуации необходимо ответить на вопрос о том, благодаря стечению каких обстоятельств она стала возможной. Особого внимания заслуживает формулировка проблемы. Действительно, четко определенная проблема может считаться наполовину решенной. Критерием правильной формулировки является наличие в определении некоего противоречия, обозначающего причину трудностей, возникающих на пути достижения организационных целей;

- интерпретация текущей ситуации. Сигнал о внешнем или внутреннем воздействии, которое может вызвать или вызвало отклонение от заданного режима функционирования системы, характеризует наличие управленческой ситуации и определяет необходимость принятия управленческого решения. Для интерпретации текущей ситуации необходима информация о состоянии факторов внешней и внутренней среды. Информацию анализируют, классифицируют, сравнивают реальные показатели с прогнозируемыми 
или запрограммированными. Подобная процедура позволяет выявить проблемы, которые необходимо решать;

- выявление факта возникновения или существования проблемы. Первый шаг на пути решения проблемы - ее определение или диагноз, полный и правильный. Как принято говорить, правильно сформулировать проблему - значит наполовину решить ее. Какое содержание вкладывается в понятие «проблема»? Проблемная ситуация характеризуется как препятствие, которое возникло при осуществлении деятельности, направленной для достижения цели. А проблема - причина возникновения препятствия. Анализируя проблемную ситуацию, необходимо вывить, какие конкретные действия или события привели к проблемной ситуации, а также, какие последствия возникли или могут возникнуть. Проблему будем определять как расхождение между желаемым и реальным состоянием управляемого объекта. Когда мы выявляем причины проблемной ситуации (определяем проблему), необходимо ответить на вопрос о том, какие обстоятельства определили возможность возникновения проблемной ситуации.

Таким образом, последовательность действий по решению управленческой проблемы, выглядит таким образом: анализ проблемной ситуации; поиск и выявление причин возникновения проблемной ситуации; формулировка проблемы; принятие решения по устранению причины возникновения ситуации. Таким образом, процесс решения управленческой проблемы проходит от установления симптомов проблемы через глубокое исследование причин возникновения установленных симптомов, далее формулировка проблемы и принятие решения по устранению проблемы. Надо понимать, что симптомы проблемы могут быть вызваны разнообразными причинами. Например, низкие продажи услуг или произведенных товаров - это симптомы проблемы. Причинами могут выступать - как низкая квалификация работников организации, так и изношенность оборудования. Поэтому очень важно на первом этапе глубоко проанализировать симптомы и причины их возникновения. Правильная формулировка проблемы есть залог ее решения. Правильная формулировка проблемы должна отвечать критерию, заключающемуся в том, что в формулировке есть определение противоречия, которое обозначает причину трудностей. 
Блок формулировка ограничений и критериев для принятия решения.

Определение критериев выбора. До проведения этапа разработки альтернатив необходимо выработать критерии, по которым они будут сравниваться. Прежде чем рассматривать возможные варианты решения возникшей проблемы, руководителю необходимо определить показатели, по которым будет производиться сравнение альтернатив и выбор наилучшей. Эти показатели принято называть критериями выбора. Например, принимая решение о приобретении нового оборудования, можно ориентироваться на критерии цены, производительности, эксплуатационных расходов, эргономичное и т. п., а в случае принятия решения о приеме на работу нового сотрудника критериями выбора среди кандидатов могут быть: образование, опыт работы, возраст, личные качества.

Разработка альтернатив. Следующий этап - разработка набора альтернативных решений проблемы. В идеале желательно выявить все возможные альтернативные пути решения проблемы, только в этом случае решение может быть оптимальным. Однако на практике руководитель не располагает (и не может располагать) такими запасами знаний и времени, чтобы сформулировать и оценить каждую возможную альтернативу. Менеджеры хорошо понимают, что поиск оптимального решения очень труден, занимает много времени и дорого стоит, поэтому они ищут не оптимальный, а достаточно хороший, приемлемый вариант, позволяющий снять проблему, и помогают отсечь заранее непригодные альтернативы и критерии выбора, определенные на предыдущем этапе. Наряду с положением, когда варианты решения проблемы заранее известны или обнаруживаются без особых трудностей, часто встречаются ситуации, при которых решаемая проблема не встречалась раньше, т. е. возможные альтернативы неизвестны, и их необходимо предварительно сформулировать. В таких случаях весьма полезным может оказаться коллективное обсуждение проблемы и генерирование альтернатив.

Выбор альтернативы. Разработав возможные варианты решения проблемы, их необходимо оценить, т.е. сравнить достоинства и недостатки каждой альтернативы и объективно проанализировать вероятные результаты их реализации. Для сопоставления вариантов решения необходимо иметь стандарты или критерии, по которым их можно сравнивать. Такие критерии выбора были установлены 
на этапе 3. С их помощью и производится выбор наилучшей альтернативы. Необходимо отметить, что поскольку выбор осуществляется, как правило, на основе нескольких, а не одного критерия, он всегда носит характер компромисса. Кроме того, при оценке возможных вариантов решения руководитель фактически имеет дело с прогнозными оценками сравниваемых величин, а они всегда являются вероятностными. Поэтому очень важно учитывать фактор риска, т. е. определять вероятность осуществления каждой альтернативы. Учет фактора риска приводит к пересмотру самого понятия наилучшего решения: им является не тот вариант, который максимизирует или минимизирует некоторый показатель, а тот, который обеспечивает его достижение с наиболее высокой степенью вероятности. Согласование решения. В современных системах управления в результате разделения труда сложилось положение, при котором подготавливают, разрабатывают решение одни работники организации, принимают или утверждают другие, а выполняют третьи. Иначе говоря, руководитель часто утверждает и несет ответственность за решение, которого не разрабатывал, специалисты, готовившие и анализировавшие решение, не участвуют в его реализации, а исполнители не принимают участия в подготовке и обсуждении готовящихся решений. Принятие управленческих решений в организации довольно часто ошибочно рассматривается как индивидуальный, а не групповой процесс. Между тем, хотя основные этапы процесса принятия управленческого решения организациями и отдельными людьми совпадают, формирование решений в организации (как было показано в гл. 1) существенно отличается от индивидуального принятия решения. Именно организация, а не отдельный руководитель должна реагировать на возникающие проблемы. И не один руководитель, а все члены организации должны стремиться к повышению эффективности ее работы. Конечно, менеджеры выбирают курс для организации, но, чтобы решение было реализовано, необходимы совместные действия всех членов организации. Поэтому в групповых процессах принятия решений весьма существенную роль играет стадия согласования. В идеальном случае исполнители будут действовать в соответствии с решениями менеджеров, однако практика далека от идеала и так происходит совсем не всегда. Признание решения редко бывает автоматическим, даже если оно явно хорошее. Поэтому руководитель должен убеждать в правильности своей точки зрения, доказывать 
работникам, что его решение несет выгоды и организации, и отдельным ее членам. Практика показывает, что вероятность быстрой и эффективной реализации значительно возрастает, когда исполнители имеют возможность высказать свое мнение по поводу принимаемого решения, внести предложения, замечания и т. п. Тогда принятое решение воспринимается как свое, а не навязанное «сверху». Поэтому лучшим способом согласования решения является привлечение работников к процессу его принятия. Разумеется, этот способ не надо абсолютизировать: встречаются ситуации, когда это невозможно или нерационально и менеджер вынужден принимать решение единолично, не прибегая к обсуждениям и согласованиям, но надо помнить, что систематическое игнорирование мнения подчиненных ведет к авторитарному стилю руководства.

Блок реализация решений. Процесс решения проблемы не заканчивается выбором альтернативы: для получения реального эффекта принятое решение должно быть реализовано. Именно это и является главной задачей данного этапа. Для успешной реализации решения прежде всего необходимо определить комплекс работ и ресурсов и распределить их по исполнителям и срокам, т.е. предусмотреть, кто, где, когда и какие действия должен предпринять и какие для этого необходимы ресурсы. Если речь идет о достаточно крупных решениях, это может потребовать разработки программы реализации решения. В ходе осуществления этого плана руководитель должен следить за тем, как выполняется решение, оказывать в случае необходимости помощь и вносить определенные коррективы. Контроль и оценка результатов. Даже после того, как решение окончательно введено в действие, процесс принятия решений не может считаться полностью завершенным, так как необходимо еще убедиться, оправдывает ли оно себя. Этой цели и служит этап контроля, выполняющий в данном процессе функцию обратной связи. На этом этапе производятся измерение и оценка последствий решения или сопоставление фактических результатов с теми, которые руководитель надеялся получить. Не следует забывать, что решение всегда носит временный характер. Срок его эффективного действия можно считать равным периоду относительного постоянства проблемной ситуации. За его пределами решение может перестать давать эффект и даже превратиться в свою противоположность - не способствовать решению проблемы, а обострять ее. В связи с этим основная задача контроля - своевременно выявлять 
убывающую эффективность решения и необходимость в его корректировке или принятии нового решения. Кроме того, осуществление этого этапа является источником накопления и систематизации опыта в принятии решений. Проблема контроля управленческих решений весьма актуальна, особенно для крупных бюрократических организаций. Можно принять немало разумных и полезных решений, но без рационально организованной системы контроля исполнения они останутся в «недрах делопроизводства» и не дадут ожидаемого эффекта.

\section{Контрольные вопросы.}

1. Какие блоки выделяют в процессе разработки и реализации управленческих решений?

2. Зачем необходима обратная связь?

3. В чем заключается этап «Разработка альтернатив»?

\section{Контрольные тесты.}

1. Стадия разработки управленческого решения «признание необходимости решения» включает в себя следующие этапы:

1) изучение ситуации;

2) выбор метода анализа ситуации;

3) интерпретация и формулирование проблемы;

4) определение критериев успешного решения проблемы.

2. Стадия разработки управленческого решения «выработка решения» включает в себя следующие этапы:

1) разработка альтернатив;

2) оченка возможных альтернатив;

3) определение критериев успешного решения;

4) выбор альтернативы.

3. Для проведения этапа генерирования альтернатив используют:

1) проведение экспертиз;

2) групповой анализ ситуации;

3) создание автоматизированных систем;

4) метод выдвижения предложений.

4. Для оценки альтернатив необходимо располагать:

1) факторами;

2) критериями принятия решений;

3) количественными оценками;

4) качественными оценками. 
5. Для оценки и сравнения выдвинутых альтернатив наиболее известным методом является:

1) метод «дерево решений»;

2) метод оптимизации;

3) метод минимизации неопределенностей;

4) метод рацчионализацчии;

6. Стадия разработки управленческого решения «реализация решения» состоит из следующих этапов:

1) организация выполнения решения;

2) анализ и контроль выполнения решения;

3) обратная связь;

4) получение информации о ходе выполнения решения.

7. Подготовка к разработке управленческого решения включает в себя следующие этапы:

1) получение информации о ситуачии;

2) определение целей;

3) разработка оченочной системь;

4) анализ и контроль.

8. В состав оценочной системы входят:

1) критерии;

2) шкальі;

3) принщииьь выбора;

4) расчет.

9. Задача этапа «анализ ситуации» состоит в том, чтобы:

1) выделить ключевые проблемы, на которые необходимо обратить внимание;

2) выявить факторы, определяюшие развитие ситуащии;

3) оценить развитие анализируемой ситуации;

4) разработать качественные и количественные оченочные системь.

10. В процесс реализации управленческого решения включены следующие элементы:

1) коллективная экспертная оценка;

2) принятие решения;

3) разработка плана действий;

4) сравнительная оченка. 


\section{ГЛАВа 3. РАЗРАБОТКА УПРАВЛЕНЧЕСКОГО РЕШЕНИЯ В УСЛОВИЯХ НЕОПРЕДЕЛЕННОСТИ И РИСКА}

Руководителям организации в современных условиях жизнедеятельности организации часто приходиться принимать управленческие решения в условиях, характеризующихся недостаточностью и ненадежностью информации. В этом случае говорят о неопределённостях и рисках. Отсутствие полной, достоверной информации, сложность ее обработки и анализа являются основными причинами возникновения неопределенности. Задача специалиста, работающего с информацией, заключается в ее поиске, выделении наиболее ценной, важной информации, оценке характеристик информации, вычленении дезинформации. Поскольку, характеристики информации оказывают влияние на уровень неопределенности, то для оценки информации используют следующие критерии: объем, полнота, достоверность, ценность, неопределенность, насыщенность. Объем управленческой информации характеризует полноту информации о каком-либо объекте управления. Он имеет три уровня оценки: информационная избыточность, субминимальный уровень, информационная недостаточность. Достоверность информации определяется соотношением (в \%) реальных сведений и общего объема информации. имеет три уровня: абсолютный $(100 \%)$, доверительный (более 80\%), и негативный (менее 80\%). Ценность информации проявляется в снижении уровня затрат ресурсов (материалов, времени, денег) на принятие правильного управленческого решения. Ценность информации имеет четыре уровня: нулевой, средний (сокращение уровня затрат или повышение прибыли более чем на 10\%), высокий (сокращение затрат более чем в 2 раза), сверхвысокий (сокращение уровня затрат более чес в 10 раз). Ценность характеризует информацию как товар, имеющий потребительскую стоимость. Насыщенность информации - это соотношение профессиональной и фоновой информации. Насыщенность имеет три уровня: высокий (80-100\%), нормативный (50-80\%), низкий (менее 50\%). Информация, которую использует руководитель для разработки управленческого решения должна иметь следующие характеристики: объем должен быть избыточный или минимальный, ценность - средняя или высокая, насыщенность должна быть нормативная. Большое влияние на неопределенности 
оказывают следующие факторы: ограничения по ресурсам (материальные, интеллектуальные и др.), воздействие обстоятельств непреодолимой силы (форм-мажорных), наличие субъективного фактора при делегировании решения или его частей большому количеству исполнителей, недостаточная профессиональная подготовка руководителей и специалистов аппарата управления, несоответствие решения объективному ожиданию объекта управления. Ограничения на ресурсы, необходимые для исполнения решения, конечно, учитываются при разработке управленческого решения. Однако в реальном процессе реализации управленческого решения могут возникнуть нежелательные сочетания таких ограничений на ресурсы, которые помешают выполнению решения. Обстоятельства непреодолимой силы (фора-мажорные) определяются как чрезвычайные, не существовавшие во время разработки или реализации управленческого решения и возникшие помимо воли его участников. Форс-мажорные обстоятельства имеют две формы: объективные и субъективные. Объективные обстоятельства имеют абсолютный характер. к ним относятся: ураганы, землетрясения, потеря сознания работником и т. д. Субъективные обстоятельства инициируются решениями высших государственных органов, выполнение которых без заметного ущерба для организации невозможно. Данный вид называют еще юридическим форс-мажором. Такие обстоятельства как изменения в составе персонала, изменение цен, банкротство или ликвидация организации и другие похожие не считаются форс-мажорными. Также существуют виды форс-мажорных обстоятельств, выделяемые по времени действия. К ним относят: длительные (войны, территориальные, финансовые ограничения государственных органов) и кратковременные (землетрясения, пожары, ураганы и др.).

К снижению качества управленческого решения относят делегирование решения или его частей большому количеству исполнителей, поскольку происходить ухудшение управляемости. Для снижения данного фактора, необходимо в процессе делегирования использовать нормы управляемости. Существуют рекомендации по количеству управленческих решений, приходящихся на руководителя. Если управленческие решения простые и одинаковые, то их может быть 21 , если однотипные простые решения, то - 17 , если разнотипные простые - 11. Если управленческие решения средние 
одинаковые, то максимальное количество, приходящееся на руководителя, должно быть - 15, если средние однотипные, то 10, если средние разнотипные, то 6. Если управленческие решения трудные одинаковые, то максимальное количество, приходящееся на руководителя, должно быть - 8, если трудные однотипные, то 5, если трудные разнотипные, то 3. Сложность решений определяется либо нормативами, либо экспертным методом.

Существование риска объективно обусловлено наличием неопределенности, которая имеет различное содержание и формы. Прежде всего, это неопределенности внешней среды, которые включают в себя разнообразные условия (экономические, социальные, этические), в которых действует организация. Если бы окружающая среда оставалась постоянной, не возникало бы никаких проблем, но она меняется, и при принятии управленческих решений менеджеру необходимо учитывать динамику этих изменений, на практике бывает очень сложно и не всегда реально. Под термином «внешняя среда» понимаются институты и факторы, находящиеся вне организации и потенциально влияющие на результаты ее деятельности. При анализе внешней среды принято различать факторы прямого воздействия и факторы косвенного воздействия. К факторам прямого воздействия относят те условия, которые способны сразу и непосредственно влиять на деятельность данной организации. Для большинства организаций внешними факторами, повышающими степень неопределенности внешней среды, являются поставщики, потребители, конкуренты, государство, контактные категории. Факторы косвенного воздействия создают общие для всех условия деятельности. Их влияние проявляется косвенно (через рабочую среду), сказывается не сразу и в большинстве случаев не носит специфического характера по отношению к конкретной организации. К этой группе факторов принято относить общие экономические, политические, социальные, научно-технические и международные условия, которые способны влиять на деятельность организации и ее результаты и должны быть учтены менеджерами при разработке и принятии решений, особенно долгосрочных. Наряду с внешней средой, источником риска является также и внутренняя среда организации. Внутренняя среда организации это та часть общей среды, которая находится в рамках организации и под контролем ее руководства. Она постоянно и самым непосредственным образом влияет функционирование и эффективность организации. Основными элементами внутренней среды организации 
являются: производство, персонал, финансы, маркетинг, организационная структура и корпоративная культура. Состояние этих ключевых элементов и рациональность их сочетания определяют конкурентный потенциал организации и уровень ка ее деятельности. Определим исходное понятие «риск», имея в виду, что оно имеет несколько значений и соответственно различный смысл. Риск - это потенциально существующая вероятность потери ресурсов или неполучения доходов, связанная с конкретной альтернативой управленческого решения. Иначе говоря, риск есть вероятность неблагоприятного исхода, т. е. того, что предприниматель или организация в результате неудачного решения понесет ущерб в виде дополнительных расходов или неполученных доходов. Итак, риск есть вероятностная категория и характеризовать и мерять его следует как вероятность возникновения определенного уровня потерь. Следовательно, оценка риска предполагает измерение возможного уровня потерь, с одной стороны, и вероятности их возникновения с другой. Риск неразрывно связан с менеджментом. Ни один менеджер в состоянии устранить риск полностью, но за счет выявления сферы повышенного риска, его количественного измерения, оценки допустимого уровня риска, регулярного проведения контроля руководитель способен владеть ситуацией и в определенной мере управлять риском. Управление рисками исходит из предложения, что при реализации решений потери (не обязательно экономические) неизбежны, но их величину можно ограничить, применение методов управления рисками приводит к тому, что размер потерь становится сопоставимым с тем выигрышем, который принесет решение. Таким образом, искусство управления риском заключается в балансировании уровней риска и потенциальной выгоды. Менеджер сопоставляет положительные и отрицательные стороны возможных решений и оценивает их вероятные последствия, т. е. определяет, насколько приемлем и оправдан риск в сравнении с возможной выгодой. Как уже отмечалось, все операции на рынке и прежде всего инвестиции так или иначе сопряжены с риском, и участникам рынка всегда приходится брать на себя самые разнообразные риски: потери имущества, финансовых потерь, снижения доходов, упущенной выгоды. Поэтому в каждом конкретном случае необходимо учитывать различные виды рисков. Это означает, что эффективность управления риском во многом зависит от его вида и требует научно обоснованной классификации. Классификация рисков позволяет четко определить место каждого вида риска в их общей системе и использовать для управления им наиболее эффективные, соответствующие именно этому виду способы и 30 
приемы. В зависимости от возможного экономического результата решения риски можно разделить на две группы: чистые и спекулятивные. Чистые риски означают возможность получения отрицательного (ущерб, убыток) или нулевого результата. К этой категории рисков относятся природные, экологические, политические, транспортные и часть коммерческих рисков: производственные и торговые. Спекулятивные риски выражаются в возможности получения как отрицательного, так и положительного (выигрыш, прибыль) результата. К ним относится другая часть коммерческих рисков - финансовые риски. В зависимости от основной причины возникновения рисков они делятся на следующие группы: природные, экологические, политические, транспортные и коммерческие. К природным рискам относится риск потерь в результате действий стихийных сил природы, например экономический ущерб в результате землетрясения, наводнения, бури, эпидемии и т.п. Экологический риск - вероятность потерь или дополнительных расходов, связанных с загрязнением окружающей среды. Политический риск риск имущественных (финансовых) потерь в связи с изменением политической системы, расстановки политических сил в обществе, политической нестабильностью. Политические риски связаны с социально-политической ситуацией в стране и деятельностью государства и не зависят от хозяйствующего субъекта. К ним относится вероятность потерь вследствие революции, массовых беспорядков, национализации предприятий, конфискации имущества, введения эмбарго, отказа нового правительства от обязательств, предшествующих и т. п. К этой категории рисков можно также отнести риск законодательных изменений, т. е. существенного изменения нормативных актов, регулирующих хозяйственную деятельность, например налогового законодательства, законодательства о валютном регулировании и т. д. Транспортный риск - это вероятность потерь, связанных с перевозками грузов различными видами транспорта: автомобильным, железнодорожным, морским, воздушным и т. д. Коммерческие риски представляют собой вероятность потерь в результате предпринимательской деятельности хозяйствующих субъектов. В соответствии с основными видами предпринимательской деятельности эта группа рисков делится на производственные, торговые и финансовые риски. Производственный риск - вероятность убытков или дополнительных издержек, связанных со сбоями или остановкой производственных процессов, нарушением технологии выполнения операций, низким качеством сырья или работы персонала и т. п. Торговый риск - риск убытков или неполу- 
чения доходов из-за невыполнения одной из сторон своих обязательств по договору, например, в результате недопоставки или несвоевременной поставки товара, задержки платежей и т. п. Финансовые риски связаны с вероятностью потерь финансовых ресурсов (денежных средств). Они подразделяются на два вида: риски, связанные с покупательной способностью денег и риски, связанные с. вложением капитала (инвестиционные риски). К рискам, связанным с покупательной способностью денег, относятся инфляционный и валютный риски. Инфляционный риск - риск того, что полученные доходы в результате высокой инфляции обесцениваются быстрее, чем растут (с точки зрения покупательной способности). Валютный риск - риск, связанный с существенными потерями, обусловленными изменениями курса иностранной валюты. Этот вид риска особенно важен и требует оценки при проведении экспортно-импортных операций и операций с валютными ценностями. Группа инвестиционных рисков весьма обширна и включает в себя системный риск, селективный риск, риск ликвидности, кредитный риск, региональный риск, отраслевой риск, риск предприятия, инновационный риск. Системный риск - риск ухудшения конъюнктуры (падения) какого-либо рынка в целом. Не связан с конкретным объектом инвестиций и представляет собой общий риск на все вложения на данном рынке (например, фондовом, валютном, недвижимости и т. д.), заключающийся в том, что инвестор не сможет их вернуть, не понеся существенных потерь. Анализ системного риска сводится к оценке того, стоит ли вообще иметь дело с данным видом активов, например акциями, и не лучше ли вложить средства в иные виды имущества, например в недвижимость. Селективный риск - это риск потерь или упущенной выгоды из-за неправильного выбора объекта инвестирования на определенном рынке. Например, неправильного выбора ценной бумаги из имеющихся на фондовом рынке при формировании портфеля ценных бумаг. Риск ликвидности - риск, связанный с возможностью потерь при реализации объекта инвестирования из-за изменения оценки его качества. Например, какого-либо объекта недвижимости (земля, строение), пакета ценных бумаг, драгоценных металлов и т. д. Кредитный (деловой) риск - риск того, что заемщик (должник) окажется не в состоянии выполнять свои обязательства. Региональный риск - риск, связанный с экономическим положением определенных регионов. Этот риск особенно свойствен так называемым монопродуктовым регионам, т. е. тем регионам, экономика которых базируется на каком-то одном товаре. Например, районам 
угле- или нефтедобычи, которые могут испытывать серьезные экономические трудности в результате изменения конъюнктуры (падение цен) на основной продукт данного региона или обострения конкуренции. Региональные риски могут возникать также в связи с политическим и (или) экономическим сепаратизмом отдельных регионов. Высокий уровень региональных рисков может быть вызван также общим депрессивным состоянием экономики ряда регионов (спад производства, высокий уровень безработицы). Отраслевой риск - риск, связанный со спецификой отдельных отраслей экономики. Эта специфика определяется двумя основными факторами: подверженностью циклическим колебаниям; стадией жизненного цикла отрасли. По этим признакам все отрасли можно разделить на подверженные циклическим колебаниям и менее подверженные циклическим колебаниям, а также на сокращающиеся (умирающие), стабильные (зрелые) и быстро растущие (молодые). Разумеется, риск предпринимательской деятельности и инвестиций в зрелые или молодые и менее подверженные циклическим колебаниям отрасли меньше. Риск предприятия связан с конкретным предприятием как объектом инвестиций. Он во многом является производным от регионального и отраслевого рисков, но вместе с тем свой вклад вносят и тип поведения, стратегия конкретного предприятия, цели и уровень его менеджмента. Один уровень риска связан с консервативным типом поведения предприятия, занимающего определенную, стабильную долю рынка, имеющего постоянных потребителей (клиентуру), высокое качество продукции (услуг) и придерживающегося стратегии ограниченного роста. Иная степень риска связана с новым, возможно, только что созданным предприятием, амбициозным менеджментом и агрессивной стратегией. Кроме того, риск предприятия включает в себя и риск мошенничества. Так, например, возможно создание ложных компаний с целью мошеннического привлечения средств инвесторов или акционерных обществ для спекулятивной игры на котировке ценных бумаг. Инновационный риск - риск потерь, связанных с тем, что нововведение, например новый товар, услуга или новая технология, на разработку которой могут быть затрачены весьма значительные средства, не будет реализовано или не окупится. Существуют своего рода правила принятия решений в условиях риска - критериев, по которым выноситься суждение об оптимальности конкретного исхода:

- правило максимаксного решения - решение принимается с ориентацией на максимизацию максимально возможного дохода. 
Это подход карточного игрока (игнорируются возможные потери, расчет на максимально возможный доход) и поэтому является рискованным подходом к принятию управленческого решения;

- правило максиминного решения - решение принимается с ориентацией на максимизацию минимально возможного дохода. Является осторожным подходом к принятию решений, так как учитывает возможные отрицательные последствия;

- правило минимаксного решения - решение принимается с ориентацией на минимизацию минимально возможных потерь. Это еще более осторожный подход к принятию решений, который учитывает все возможные риски (учитываются не только реальные потери, но и упущенные возможности);

- критерий Гурвича: является компромиссом между максимаксным и максиминным решениями.

Контрольные вопросы.

1. Чем отличаются неопределенность и риск?

2. В чем заключается сущность методов управления рисками?

3. Чем отличаются решения, принимаемые в условиях определенности и в условиях риска?

\section{Контрольные тесты.}

1. Риск - это:

1) потенциильно существующая вероятность потери ресурсов или неполучения доходов, связанная с конкретной альтернативой управленческого решения;

2) вероятность благоприятного исхода, т.е. экономии ресурсов или получения дополнительных доходов;

3) измерение возможного уровня потерь;

4) условие протекания производственных, коммерческих и финансовых операций.

2. По признаку происхождения риски бывают:

1) вероятные;

2) чистые;

3) спекулятивные;

4) прогнозируемыле.

3. К чистым рискам относятся:

1) природно-естественные;

2) экологические;

3) политические;

4) финансовые. 
4. К спекулятивным рискам относятся:

1) финансовые;

2) экологические;

3) транспортнье;

4) торговые.

5. К категории природных рисков относятся:

1) землетрясения;

2) транспортные;

3) производственные;

4) инфляционнье.

6. Спекулятивные риски выражаются в возможности:

1) получения отрицательного или нулевого результата;

2) потерь в результате действия стихийных сила природы;

3) получения как отрицательного, так и положительного результата;

4) потерь от предпринимательской деятельности.

7. Коммерческие риски представляют собой:

1) вероятность потерь в результате предпринимательской деятельности хозяйствующих субъектов;

2) вероятность потерь, связанных с перевозками грузов;

3) риск того, что полученные доходы в результате высокой инфлящии обесчениваются быстрее, чем растут (с точки зрения покупательной способности);

4) вероятность потерь, связанных с экономическим кризисом.

8. Риск ухудшения конъюнктуры:

1) кредитный риск;

2) риск ликвидности;

3) валютный риск;

4) селективный.

9. Степень риска:

1) количественно характеризует вероятность негативных результатов принятого решения;

2) дает количественную характеристику вероятных потерь;

3) предполагает измерение степени риска с помощью методов математической статистики и теории вероятностей;

4) заключается в качественной или количественной оценке возможных потерь и вероятности их возникновения. 
10. Цена риска дает:

1) качественную характеристику вероятных потерь;

2) количественную характеристику вероятных потерь;

3) количественную и качественную характеристику вероятных nomeps;

4) оценку вероятности неблагоприятного исхода.

11. К методам, имеющим цель компенсировать причиненный организации ущерб, следует отнести метод:

1) страхование;

2) экспертиза;

3) распределения риска;

4) диверсификация рисков.

12. С помощью статистического метода можно оценить:

1) коммерческий риск;

2) экологический риск;

3) транспортнылй;

4) политический.

13. Качественная оценка риска реализуется в форме:

1) составления рейтингов;

2) составления анкет;

3) построения кривой риска;

4) определения зон риска.

14. Графическое изображение зависимости вероятности потерь от их величины называют:

1) кривой риска;

2) зоной риска;

3) кривой потерь;

4) область потерь.

15. К группе инвестиционных рисков относятся:

1) инновационные риски;

2) инфляционнылй риск;

3) производственный риск;

4) системный риск.

16. Неопределенность рассматриваю как:

1) явление;

2) факт;

3) свойство,

4) операцию. 
17. Неопределенности бывают:

1) объективные;

2) индивидуальные;

3) групповые;

4) субъективные.

18. Высокий уровень неопределенности подразумевает:

1) необходимость пересмотра некоторых этапов разработки и реализачии решения;

2) невозможность адекватной оценки и интерпретаџии данных о складывающейся ситуащии;

3) разработку новых прочеедр;

4) необходимость изменения основных этапов разработки и реализации управленческого решения.

19. Неопределенность в процессе разработки управленческого решения может быть вызвана:

1) отсутствием достоверной информации;

2) сложностью при обработке информации;

3) наличием отрицательных характеристик информации;

4) наличием положительных характеристик информации.

20. К рискам, связанным с покупательной способностью денег, относятся:

1) кредитныци риск;

2) риск ликвидности;

3) валютный риск;

4) селективный.

21. Зона допустимого риска:

1) область, в пределах которой, величина вероятных потерь не превышает ожидаемой прибыли;

2) область возможных потерь, превышающих величину ожидаемой прибыли вплоть до величины полной расчетной выручки;

3) область вероятных потерь, которые превосходят критический уровень и могут достигать величины, равной собственному капиталу организачии;

4) область вероятных потерь, где величина прибыли подчинена нормальному закону распределения. 
22. Зона катастрофического риска:

1) область, в пределах которой, величина вероятных потерь не превынает ожидаемой прибыли;

2) область возможных потерь, превымающих величину ожидаемой прибыли вплоть до величины полной расчетной выручки;

3) область вероятных потерь, которые превосходят критический уровень и могут достигать величины, равной собственному капиталу организации;

4) область вероятных потерь, где величина прибыли подчинена нормальному закону распределения.

23. Зона критического риска:

1) область, в пределах которой, величина вероятных потерь не превымает ожидаемой прибыли;

2) область возможных потерь, превымающих величину ожидаемой прибыли вплоть до величины полной расчетной выручки;

3) область вероятных потерь, которые превосходят критический уровень и могут достигать величины, равной собственному капиталу организации;

4) область вероятных потерь, где величина прибыли подчинена нормальному закону распределения.

24. С целью построения кривой риска и определения зон и показателей допустимого, критического и катастрофического рисков может, использован метод:

1) поглощуения рисков;

2) экспертный;

3) индивидуальныли;

4) групповой.

25. Правило математического сложения рисков:

1) если риски относятся к разным областям деятельности и проявления негативных факторов происходят независимо друг от друга, то вероятность их проявления оченивается по правилам теории вероятностей для суммы вероятностей независимых событий, а ичена риска оченивается как средняя арифметическая;

2) если риски относятся к одной области деятельности, но проявление негативных факторов происходит независимо друг от друга, то вероятность их проявления оценивается по максимальному значению; 
3) если риски относятся к разным областям деятельности, но негативные факторы проявляются в зависимости друг от друга, то степень риска рассчитьвается как сумма произведений риска одного события на шансы других;

4) если цена риска предшествующего этапа реализации решения превышает иену риска последующего, непосредственно связанного с первым, то второй исключается из расчетов.

26. К методам управления рисками относятся:

1) метод распределения риска;

2) метод разработки специальных инструкиий;

3) метод предупреждения и ограничения риска;

4) групповой метод. 


\section{Глава 4. МЕТОДЫ ПРИНЯТИЯ УПРАВЛЕНЧЕСКИХ РЕШЕНИЙ}

Методы переработки информации в процессе разработки и принятии управленческого решения грают огромное значение, так как в его основе лежит информация. Все методы принятия управленческих решений можно объединить в три группы: неформальные (эвристические), коллективные, количественные.

Неформальные (эвристические) методы принятия решений. Часто информация, используемая в процессе разработки управленческого решения, не обладает количественными показателями. Обработать и оценить такую информацию можно исходя из интуиции, обобщений, представлений, опыта, ассоциаций. Беседы, обсуждения, задания наводящих вопросов можно получить новую существенную информацию от клиента, партнера и другого носителя нужных сведений - это формы получения новой существенной информации качественного характера. Такие методы называются эвристическими. Неформальные методы основаны на аналитических способностях лиц, принимающих решения. Это совокупность логических приемов и методики выбора оптимальных решений руководителем, теоретическое сравнение альтернатив с учетом накопленного опыта. Неформальные методы базируются в основном на интуиции менеджера. Их преимущество состоит в том, что они принимаются оперативно. Недостатком этих методов является то, что они не гарантируют от выбора ошибочных решений, поскольку интуиция может подвести менеджера.

Коллективные методы обсуждения и принятия решений. К данной группе методов относят такие виды как, заседание, совещание, работа в комиссии и т. п. Основным моментом в коллективной работе над реализацией управленческих решений является определение круга лиц - участников данной процедуры. Главными критериями формирования такой группы являются компетентность, способность решать творческие задачи, конструктивность мышления и коммуникабельность. Наиболее распространен такой метод коллективной подготовки управленческих решений, как «мозговой штурм», или «мозговая атака» - совместное генерирование новых идей и последующее принятие решений. Если предстоит решить сложную проблему, собирается группа людей, которые предлагают 
любые решения определенной проблемы. Основное условие «мозгового штурма» - создание обстановки, максимально благоприятной для свободного генерирования идей. Чтобы добиться этого, запрещается опровергать или критиковать идею, какой бы фантастичной она ни была. Все идеи записываются, а затем анализируются специалистами. Примером коллективного принятия решений может служить метод Дельфы, получивший название от греческого города Дельфы, прославившегося жившими там мудрецами. Метод Дельфы - многоуровневая процедура анкетирования. Суть метода состоит в том, что каждый эксперт отвечает на вопросы независимо и анонимно. Затем все ответы анализируются и в сводном виде доводятся до каждого эксперта. После каждого тура данные анкетирования дорабатываются и полученные результаты сообщаются экспертам с указанием расположения оценок. Первый тур анкетирования проводится без аргументации, во втором отличающийся от других ответ подлежит аргументации или же эксперт может изменить оценку. После стабилизации оценок опрос прекращается и принимается предложенное экспертами или скорректированное решение. Среди коллективных методов принятия решений существует японская кольцевая система принятия решений - «кингисе», суть которой состоит в том, что на рассмотрение готовится проект новшества. Он передается лицам для обсуждения по списку, составленному руководителем. Каждый должен рассмотреть предлагаемое решение и дать свои замечания в письменном виде. После этого проводится совещание, на которое, как правило, приглашаются те специалисты, мнение которых руководителю не совсем ясно. Эксперты выбирают свое решение в соответствии с индивидуальными предпочтениями. И если они не совпадают, то возникает вектор предпочтений, который определяют с помощью одного из следующих принципов: большинства голосов - выбирается решение, имеющее наибольшее число сторонников; диктатора - за основу берется мнение одного лица; принцип Курно используется в том случае, когда коалиции нет, т. е. предлагается число решений, равное числу экспертов. В этом случае необходимо найти такое решение, которое отвечало бы требованию индивидуальной рациональности без ущемления интересов каждого в отдельности; принцип Парето используется при принятии решений, когда все эксперты образуют единое целое, одну коалицию. В этом случае оптимальным будет такое решение, которое невыгодно менять сразу 
всем членам группы, поскольку оно объединяет их в достижении общей цели и др. Количественные методы принятия решений. Как правило разработчики управленческого решения используют алгоритмический метод переработки информации. Данный метод предполагает строгую формализацию выполнения процедур и операций на основе правил, формул, алгоритмов, статистических данных. Например, экономический анализ эффективности нового производства. В их основе лежит научно-практический подход, предполагающий выбор оптимальных решений путем обработки больших массивов информации. В зависимости от типа математических функций, положенных в основу моделей, различают: линейное моделирование, при котором используются линейные зависимости; динамическое программирование, позволяющее вводить дополнительные переменные в процесс решения задач; вероятностные и статистические модели, реализуемые в методах теории массового обслуживания; теория игр - моделирование таких ситуаций, принятие решения в которых должно учитывать несовпадение интересов различных подразделений; имитационные модели позволяют экспериментально проводить реализацию решений, изменить исходные предпосылки, уточнить требования к ним.

В основе количественных методов лежит научно-практический подход, предполагающий выбор оптимальных решений путем обработки с помощью компьютера больших массивов информации. Анализ временных рядов - основан на допущении, согласно которому, случившееся в прошлом дает достаточно хорошее приближение в оценке будущего. Данный метод анализа часто используется для оценки: спроса на товары и услуги, оценки потребности в товарных запасах, прогнозирования структуры сбыта, потребности в кадрах.

Причинно-следственное моделирование. Наиболее хитроумный и математически сложный количественный метод. Это попытка спрогнозировать то, что произойдет в подобных ситуациях, путем исследования статистической зависимости между рассматриваемым фактором и другими переменными. Пример: прогнозирование спроса - уровень личных доходов, демографические изменения, появление новых конкурентов и др.

Теория игр - метод моделирования, оценки воздействия принятого решения на конкурентов (изначально разработали военные, чтобы в стратегии учесть действия противников). Пример: если с 
помощью теории игр руководство торговой фирмы приходит к выводу, что в случае повышения цен на товар конкуренты не сделают того же, то целесообразно отказаться от решения повысить цены, чтобы не попасть в невыгодное положение.

Математическое моделирование. Применяют в тех случаях, когда управленческое решение принимается на основе обширной цифровой информации.

\section{Контрольные вопросы.}

1. Какие группы методов принятия управленческих решений вы знаете?

2. В каких ситуациях следует использовать те или иные методы принятия решений?

3. Что характерно для коллективных методов принятия решений?

4. Что относится к неформальным методам принятия управленческих решений?

5. Что лежит в основе количественных методов принятия управленческих решений?

Контрольные тесты.

1. Метод «Дельфы» состоит в проведении:

1) открытой дискуссии по обсуждаемой проблеме, результат определяется голосованием;

2) обсуждения проблемы группой, состоящей из 3-10 рядовых исполнителей;

3) многоуровневого анкетирования экспертов;

4) обсуждения группой из 4-5 человек в результате, которого, составляются прогнозы желательного и нежелательного будуusezo.

2. К основным особенностям метода «Дельфы» относятся:

1) открытость обсуждения;

2) анонимность суждениц̆;

3) наличие обратной связи;

4) разнообразие точек зрения;

3. К наиболее часто встречающимся методам коллективной выработки управленческого решения относятся:

1) «кружки качества»;

2) круговой метод;

3) метод прямого воздействия;

4) выбора альтернатив. 
4. Метод коллективной выработки управленческих решений «Метаплан» состоит в проведении:

1) собрания группы из 3-10 рядовых исполнителей во главе с руководителем для обсуждения проблем управления качеством;

2) открытой дискуссии по обсуждаемой проблеме для выработки едино мнения экспертов;

3) собрания группь из 4-5 человек, которая составляет прогнозы желательного и нежелательного будущего и в соответствии с ними высказывает идеи о направлениях деятельности фирмьл.;.

4) сбора информащии для создания «биржи информаџии» от группы в 15-20 человек, которым поручено выявить имеющуюся проблему или ряд проблем, связанные с ними экономические потери или открывающиеся возможности.

5. Метод коллективной выработки управленческих решений «Утопических игр» направлен на:

1) выработку прогнозов и идей о направления деятельности фирмы в соответствии с ними;

2) поименного выдвижения предложений;

3) рассмотрение проекта новщества и дачу своих замечаний в письменном виде лицами по списку, составленному руководством;

4) выработку единого мнения экспертов по обсуждаемой проблеме.

6. Главными критериями формирования группы экспертов являются:

1) природнье свойства: особенности высшей нервной деятельности, памяти, эмочиий и т.д.;

2) способность работать в группе;

3) компетентность;

4) привычки.

7. Коэффициенты ранговой корреляции используются для того, чтобы оценить:

1) альтернативь;

2) согласованность экспертов;

3) работоспособность экспертов;

4) профессионализм экспертов. 
8. Ответ на вопрос о том, насколько оптимально сформирован творческий коллектив с точки зрения коммуникации и интеракции, можно получить с помощью:

1) сочиограммы;

2) интеракционного анализа;

3) наблюдения за группой;

4) эксперимента.

9. Вектор индивидуальных предпочтений определяют с помощью принципов:

1) оптимизачии;

2) распределения мнений;

3) принципа диктатора;

4) принциип большинства голосов.

10. К стратегиям выработки группового решения относятся:

1) стратегия простого или квалифицированного больиинства;

2) стратегия суммирования рангов;

3) стратегия минимизации отклонений;

4) стратегия максимизации отклонений.

11. Какие типичные особенности группового мышления снижают его эффективность:

1) групповое давление;

2) влияние престижа и уровня компетенции;

3) эмочиональность;

4) «размывание «риска.

12. При применении метода «мозговая атака» выделяют следующие этапы

1) организационный (постановочный);

2) генерационныли;

3) согласований;

4) креативнылй.

13. К разновидностям моделей принятия управленческих решений относятся:

1) Модель «естественной» организаџии;

2) Институцчиональная модель;

3) Индивидуальные модели;

4) Корпоративные модели. 
14. Дескриптивные модели применяют для:

1) описания свойств и параметров прочесса принятия решений с иелью прогнозирования его хода в будущем;

2) управления процессом принятия решений, формирования его сущностных элементов и его развития;

3) управления процессами ожиданий и системы ценностей членов организачии;

4) управления принятыми в группе нормами поведения.

15. Нормативные модели принятия решений применяют для:

1) описания свойств и параметров прочесса принятия решений с иелью прогнозирования его хода в будущем;

2) управления прочессом принятия решений, формирования его сущностных элементов и его развития;

3) управления процессами ожиданий и системы ценностей членов организачии;

4) управления принятыми в группе нормами поведения.

16. Индуктивные модели принятия решений строятся:

1) для описания свойств и параметров прочесса принятия решений с иелью прогнозирования его хода в будущем;

2) с учетом наличия условий для проведения экспериментов, а также возможностей современных управленческих технологий;

3) на внедрении новых методов моделирования применительно к конкретной проблемной ситуации принятия решения;

4) путем обобщения наблюдений по единичным частным фактам, которые считаются важными для принятия управленческого решения.

17. Проблемно-ориентированные модели принятия решений строятся:

1) для описания свойств и параметров прочесса принятия решений с целью прогнозирования его хода в будущем;

2) с учетом наличия условий для проведения экспериментов, а также возможностей современных управленческих технологий;

3) на внедрении новых методов моделирования применительно к конкретной проблемной ситуации принятия решения;

4) путем обобщения наблюдений по единичным частным фактам, которые считаются важными для принятия управленческого решения. 
18. Модели развития принятия решения строятся:

1) для описания свойств и параметров процесса принятия решений с иелью прогнозирования его хода в будущем;

2) с учетом наличия условий для проведения экспериментов, а также возможностей современных управленческих технологий;

3) на внедрении новых методов моделирования применительно $\kappa$ конкретной проблемной ситуации принятия решения;

4) путем обобщения наблюдений по единичным частным фактам, которые считаются важныли для принятия управленческого решения.

19. Согласно модели организации «организация - машина»:

1) организации возникают естественным образом и развиваются по собственным законам;

2) организация представляется как безличный механизм - многоуровневой административной иерархии, состоящей из формализованных структур, связей, системы взаимоотномений между ее членами;

3) главным регулятором в организачии являются принятые в группе нормы поведения;

4) основное внимание должно уделяться роли ожиданий и системы иенностей членов организации, их представлениям о ситуации, взаимодействию между членами организации.

20. Согласно модели «естественной организации:

1) организации возникают естественным образом и развиваются по собственным законам;

2) организация представляется как безличный механизм - многоуровневой административной иерархии, состоящей из формализованных структур, связей, системы взаимоотношений между ее членами;

3) главным регулятором в организаџии являются принятые в группе нормы поведения;

4) основное внимание должно уделяться роли ожиданий и системы ценностей членов организачии, их представлениям о ситуации, взаимодействию между членами организациии. 
21. Согласно модели «организация - община»:

1) организации возникают естественным образом и развиваются по собственным законам;

2) организачия представляется как безличный механизм - многоуровневой административной иерархии, состоящей из формализованных структур, связей, системы взаимоотношений между ее членами;

3) главным регулятором в организации являются принятые в группе нормы поведения;

4) основное внимание должно уделяться роли ожиданий и системы ценноостей членов организации, их представлениям о ситуации, взаимодействию между членами организащии.

22. Согласно интеракционистской модели организации:

1) особое значение в структуре организации придается влиянию технологического прочесса производства на внутригрупповые связи;

2) внутри организаџии сталкиваются и противодействуют друг другу противоположные иели и институции;

3) главным регулятором в организации являются принятые в группе нормы поведения;

4) основное внимание должно уделяться роли ожиданий и системы иенностей членов организации, их представлениям о ситуации, взаимодействию между членами организации.

23. Согласно институциональной модели организации:

1) особое значение в структуре организачии придается влиянию технологического прочесса производства на внутригрупповые связи;

2) внутри организаџии сталкиваются и противодействуют друг другу противоположные цели и институции;

3) функиионирование и структура организаџии формируется под воздействием институциий - традиций и норм, действующих во внутренней и внешней среде функиионирования организации;

4) основное внимание должно уделяться роли ожиданий и системы иенностей членов организации, их представлениям о ситуации, взаимодействию между членами организации. 
24. Согласно конфликтной модели организации:

1) особое значение в структуре организации придается влиянию технологического процесса производства на внутригрупповые связи;

2) внутри организации сталкиваются и противодействуют друг другу противоположнье цели и институции;

3) функционирование и структура организации формируется под воздействием институцุий - традиций и норм, действующฺх во внутренней и внешней среде функичонирования организащии;

4) основное внимание должно уделяться роли ожиданий и системы ценностей членов организации, их представлениям о ситуации, взаимодействию между членами организации.

25. Согласно конфликтной модели организации:

1) особое значение в структуре организации придается влиянию технологического проиесса производства на внутригрупповые связи;

2) внутри организации сталкиваются и противодействуют друг другу противоположные цели и институции;

3) функционирование и структура организации формируется под воздействием институций - традиций и норм, действующих во внутренней и внешней среде функционирования организации;

4) основное внимание должно уделяться роли ожиданий и системы иенностей членов организации, их представлениям о ситуации, взаимодействию между членами организации.

26. Модель принятия решения это:

1) упрощченное представление предмета, системы или прочесса в форме, отличной от формы иелого;

2) приемы, принятые для достижения какой-либо ичели;

3) мероприятия, операции, принятые для достижения какойлибо иели;

4) сложное представление предмета в простой форме. 


\section{ГЛАВа 5. КАЧЕСТВО ПРИНИМАЕМОГО УПРАВЛЕНЧЕСКОГО РЕШЕНИЯ}

Понятие качества управленческого решения достаточно неоднозначно: во-первых, потому что в полной мере оно может быть оценено только после того, как решение реализовано; во-вторых, недостатки в реализации могут свести на нет высокое качество решения на этапе его теоретического обоснования. Качество управленческого решения - это частное проявление общего понятия качества. Последнее может быть определено как совокупность свойств и особенностей объекта, и достигаемая в соответствии с этим степень удовлетворения потребности в нем. Понятие качества имеет объективные характеристики, которые фиксируются в нормативных документах (ГОСТы, ТО и т. п.). Однако для каждого конкретного потребителя качество имеет и свои индивидуализированные признаки, которые определяются особенностями данной личности и ее потребностью. Качество управленческого решения - это степень соответствия выработанных теоретических рекомендаций по обоснованию цели и путей ее достижения той реальной проблеме, которая является предметом решения.

Первым общепринятым условием качества управленческого решения является его научная обоснованность, т. е. знание объективных законов развития системы и конкретного объекта, применительно к которому принимается решение. Необходимо уметь прогнозировать тенденции развития объекта управления, располагать полной, достоверной, своевременной информацией, знать основные рекомендации теории принятия решения. Вторым условием является системность, которая включает, с одной стороны, логическую связь между целями и методами их достижения, с другой единство подхода к решению разных проблем, связанных между собою, вытекающее из стратегии организации. Третье условие своевременность принятия решения, которая означает, что время, затраченное на принятие и реализацию решения, должно соответствовать реальным условиям функционирования объекта, т. е. результат должен быть получен в тот срок, когда он может быть в полной мере эффективен. Совершенно очевидно, что первые два условия находятся в противоречии с третьим, поскольку научная обоснованность включает сбор информации, который требует вре- 
мени, а системность предполагает формулирование принципов построения системы решения, что также требует времени. В реальной жизни разрешение этого противоречия достигается на основе либо накопленного практического опыта, либо интуиции лица, принимающего решение.

Четвертое условие: следует помнить, что качество решения понятие относительное, что при изменении ситуации возникает необходимость либо частично изменить, либо полностью отказаться от принятого решения. Это вовсе не означает, что данное решение было в принципе неправильно. Психологически следует быть готовым к тому, что такая ситуация возникнет, необходимо рассматривать ее как совершенно нормальную и уделять больше внимания прогнозированию развития ситуации и формулированию запасных вариантов реакции на эту ситуацию. Пятое условие практичность. Любое самое великолепное решение будет абсолютно бессмысленным, если организация не располагает возможностями для его реализации в ограниченные сроки и при имеющихся ресурсах. Этот вопрос подробно рассмотрен выше. Шестое условие качества решения - его правомочность. Это означает, что решение должно приниматься тем лицом или органом, которое имеет соответствующее законное основание его принимать. Повышению качества решения способствует также четкая отработка процедуры принятия решения. К факторам качества управленческого решения относят: факторы ситуационного характера, оказание проблемы, научное предсказание, анализ и прогноз, метод получения информации, организация управления, факторы поведенческого характера, стиль поведения, политическая и социальная среда, моральные и правовые нормы, мотивы и интересы, личность руководителя. Несоблюдение рассмотренных факторов приводит к снижению качества управленческих решений.

Низкое качество управленческих решений также связано с их огромным количеством, неконкретным характером рекомендаций, имитирующих решение проблемы (ускорить разработку, повысить качество, предотвратить), без указания конкретных мер и сроков, отсутствие делегирования, приводящее к чрезмерной перегрузке руководителя и усилению отрицательного воздействия личностных факторов: низкий авторитет руководителя, решение которого вызывает сомнение у исполнителей и потому удлиняет сроки реализации решения, приводит к конфликтам в коллективе. Низкий 
авторитет руководителя может быть связан с переоценкой им собственной квалификации, неуверенностью в себе, неумением четко и ясно изложить свою позицию, взять на себя ответственность за принимаемое решение.

Необходимость постоянного повышения качества решения должна базироваться на правильном подборе кадров на должности, связанные с принятием решения. В основе подбора должны лежать прежде всего соответствующие личностные характеристики, поскольку недостаток квалификации может быть преодолен путем систематического ее повышения как в области общей теории менеджмента, так и в теории принятия управленческих решений.

Успешное руководство предприятием во многом определяется содержанием принимаемых решений и обеспечением точного и своевременного их исполнения. По данным некоторых исследований, причиной неисполнения каждого третьего решения является недоработка решения руководителем на стадии его формирования. Поэтому вопросы обеспечения качества управленческих решений являются одними из основных, требующих особого внимания руководителей. Для того, чтобы в процессе реализации управленческих решений достигались цели, поставленные при их разработке, необходимо, чтобы решения отвечали следующим требованиям: соответствие действующему законодательству, уставным документам организации. Для обеспечения выполнения этого требования руководитель должен обладать знаниями в области административного, трудового, налогового законодательства, решения должны быть согласованы с юристами организации, а в сложных или спорных ситуациях руководитель может обратиться за консультацией к внешним специалистам (например, в консалтинговые фирмы или агентства); соответствие общему направлению развития компании, задаваемому принятой стратегией. Решения будут некачественными даже при самой глубокой и тщательной проработке, если они идут вразрез с решениями, принимаемыми руководителями других структурных подразделений или с ранее принятыми решениями. Поэтому необходимо согласование решения не только с вышестоящим руководством, но и теми производственными единицами, которые будут участвовать в процессе реализации решения; соответствие служебному положению руководителя и объему его полномочий, прав и обязанностей. Для обеспечения 
этого требования разрабатываются должностные инструкции руководителя, подчиненных, положения об отделах и службах, в которых четко прописываются права, обязанности, ответственность руководителя; наличие в тексте управленческого решения четкого механизма его реализации, т. е. каждый исполнитель должен понимать, что именно он делает, в какие сроки, с какой целью, а также как будет осуществляться контроль исполнения (кем и по каким параметрам) и какие предусмотрены механизмы стимулирования или мотивации труда; наличие достаточного объема ресурсов для исполнения решения, а также организационных механизмов, позволяющих реализовать решение; возможность нарушения процедуры исполнения решения либо отклонения получаемых результатов от запланированных. Следует учитывать объективные и субъективные риски. Объективные риски проистекают из событий или явлений внешней и внутренней среды и вероятность появления каждого из этих рисков, а также отрицательные последствия могут быть определены и учтены при разработке решения. Субъективные риски возникают в связи с индивидуальностью мышления каждого человека, и они проявляются в том, что исполнителем может быть неправильно понято задание, руководитель может недостаточно подробно объяснить задание, полагая, что подчиненный уже в нем разобрался. Кроме того, следует принимать во внимание и разные стили мышления мужчин и женщин, когда мужчины лучше воспринимают конкретные объекты и четкие указания, а женщины образы и состояния («мужчины видят деревья, а женщины - лес»); своевременность решения. При наступлении ситуации, когда надо принимать решение, ситуация продолжает развиваться, и если руководитель затягивает разработку решения, то у подчиненных остается меньше времени на его реализацию. С другой стороны, решение не должно быть поспешным, так как недостаточная его проработанность может вызвать не менее тяжелые последствия, чем опоздание с реализацией решения; быть эффективным, т. е. давать положительный результат, превышающий затраты на его разработку и реализацию. Данное требование является одним из основных в условиях рыночной экономики. Однако часто руководителю требуется принять решение, приносящее социальный эффект, выразить который в денежных единицах затруднительно, поэтому можно сказать о том, что решение должно либо приносить положительный эффект, либо предупреждать негативные последствия и 
убытки, возможные в случае бездействия; должным образом оформлено. Несмотря на некоторую бюрократичность данного требования, оно все же является обязательным, так как невыполнение этого требования может лишить решение юридической силы и даже стать причиной судебного разбирательства. К погрешностям оформления решения можно отнести отсутствие обязательных реквизитов на документах, подписи лиц, с которыми необходимо согласовать решение, нечеткое разделение решения на констатирующую и постановляющую части, отсутствие в тексте решения ключевых слов, таких как «приказываю», «предлагаю» и другие причины.

При соблюдении данных требований управленческое решение будет являться необходимым для организации и обеспечит реализацию поставленных общих целей.

Любое управленческое решение в свою очередь зависит от ряда факторов, к которым по относятся: качество исходной информации, определяемое ее достоверностью, достаточностью, защищенностью от помех и ошибок, формой представления информации. Здесь следует помнить, что точность результатов расчета не может быть выше точности использованной информации; оптимальный или рациональный характер разрабатываемого решения; актуальность решения для организации, которая определяется потребностью в изменениях в определенный момент времени или в течение определенного временного интервала; соответствие принимаемого решения механизмам управления организации и принятых методов управления; квалификация руководителя и исполнителей; готовность управляемой системы к исполнению принятых решений.

Также, управленческое решение должно быть устойчивым по эффективности к возможным ошибкам в определении исходных данных. Решение также должно быть гибким, т. е. предусматривать возможность координации действий в случае возникновения ранее не предусмотренных обстоятельств, искажающих результаты решения.

Качество является одной из самых важных характеристик товара, продукции, работы либо услуги. Управленческое решение можно определить как один из видов услуг, оказываемых управленческими работниками организации. Поскольку руководитель или группа лиц, принимающих решение, являются в большей части 
наемными работниками и получают вознаграждение за свою деятельность, то должно обеспечиваться соответствующее качество решений.

Качество товара, продукции, работ, услуг можно определить как степень их соответствия предъявляемым к ним требованиям. Данная степень соответствия техническим, эргономическим, экологическим, экономическим и другим нормам определяет, насколько будет удовлетворен потребитель товаром, продукцией, работой или услугой. Применительно к управленческому решению можно сказать, что данная услуга востребована, с одной стороны, собственниками предприятия, а с другой - потребителями продукции, производство которой обеспечивает управленческая деятельность. Поэтому качество управленческого решения можно определить как степень удовлетворения результатами решения непосредственно лица, принимающего решение, собственников организации и потребителей продукции организации Для обеспечения качества управленческого решения необходимо, чтобы были найдены ответы на следующие вопросы: руководитель какого уровня управления должен принимать решение; тип принимаемого решения; сколько времени руководитель может потратить на разработку решения и сколько времени остается исполнителям для реализации решения; каким образом должно быть оформлено решение; каким образом решение доводится до подчиненных; какие показатели контроля исполнения решения будут использованы; какова степень ответственности исполнителей за реализацию решения и руководителя за своевременность и эффективность решения?

Принадлежность руководителя к определенному уровню управления необходимо знать при оценке качества решения, так как на более низких уровнях управления решения более типичные, менее ответственные, поэтому достаточно легко обеспечить их выполнение и оценить степень соответствия принятым нормам или требованиям. Здесь качество управленческого решения определяется в большей степени тем, насколько результаты решения соответствуют ожиданиям менеджеров, и в меньшей степени - собственников предприятия и потребителей. На более высоких уровнях управления решения преимущественно творческого характера, некоторые являются уникальными, поэтому здесь важным становится соответствие результатов решения ожиданиям потребителей и собственников. 
Тип принимаемого решения важен для определения способов разработки и исполнения решения. Например, если это традиционное решение, то порядок его разработки и реализации налажен, поэтому качество решения достаточно легко определяется степенью соответствия результата решения установленным требованиям. Если решение принимается группой с учетом мнения узких специалистов по тематике принимаемого решения, то это, как правило, более продуманные и обоснованные решения, поэтому их качество ожидается выше, чем у подобных решений, принятых руководителем единолично. Время на разработку решения должно быть достаточным для изучения всех аспектов решаемой проблемы, но, с другой стороны, исполнители должны успеть реализовать решение для того, чтобы результат решения был востребован. Оформление решения может занять определенное время, причем чем больше требуется получить согласований, тем меньше времени останется для исполнения решения. Доведение решения до подчиненных является достаточно ответственным этапом, так как чем понятнее будет изложена цель решения, распределены обязанности по исполнению решения, тем быстрее решение будет реализовано и получен требуемый результат. Показатели контроля исполнения решения нужны для того, чтобы определить, является ли решение реализованным. Без этих показателей определить качество решения достаточно трудно.

Мера ответственности должна особо оговариваться в случаях, когда решение имеет высокую значимость для организации. Качество управленческого решения - это многогранное понятие, которое включает в себя организационные, экономические, социальные, технологические, правовые, экологические, политические, этические, психологические и иные аспекты. Организационная сторона качества управленческого решения регулируется инструкциями, принятыми в компании. Экономические аспекты качества определяются оценкой экономической эффективности реализованного решения. Социальный аспект качества решения регулируется нормами социального поведения и правами человека. С технологической стороны качество решения должно опираться на принятые технические нормативы или стандарты. С правовой точки зрения, управленческое решение должно соответствовать национальным и международным законодательным актам, с политической - про- 
грамме национального развития, с этической точки зрения принятым в организации правилам поведения, традициям. Важнейшими из условий обеспечения качества управленческих решений являются информационные. Вся информация может быть трех видов: подсознательная, или интуитивная. Ее источниками могут выступить опыт предыдущих поколений, благоприобретенный опыт, знания, полученные в процессе обучения, и т. п. Воображение позволяет преобразовать эту информацию в более или менее формализованный результат прогноза. Такая информация используется при экспертном прогнозировании, и результатом может быть как количественный прогноз (план), так и качественный (хуже, лучше; больше, меньше); предметная - описание процесса или состояния объекта дается естественным языком. Это позволяет получить результат прогноза с использованием формальных методов математической логики и логики предложений. Результат прогнозирования может иметь только качественный характер; формальные статистические данные, которые получают на этапе анализа объекта прогнозирования или используя данные официальной статистики. Результатом их использования будут количественные оценки.

Все управленческие решения могут быть разбиты на группы в зависимости от того, на каком уровне власти они принимаются. Менеджерами низшего звена управления принимаются обычно типовые решения, которые разрабатываются согласно установленному порядку, процесс их разработки осуществляется периодически или по предписанию. Для решений, принимаемых на этом уровне управления, характерны оперативность, невысокая значимость для организации в целом, определенность результата. В связи с этим можно выделить следующие показатели качества управленческих решений, разработка и принятие которых осуществляются менеджерами низшего звена управления: доля решений, разработанных по предписанию вышестоящей организации либо более высокого уровня власти в организации, реализованных в установленные сроки; доля решений, разработанных по предписанию вышестоящей организации либо более высокого уровня власти в организации, реализованных с требуемым результатом; доля решений, разработанных по предписанию вышестоящей организации либо более высокого уровня власти в организации, в которых сложность задания увеличена по собственной инициативе разра- 
ботчика решения; доля самостоятельно разработанных и реализованных решений; количество нарушений трудовой дисциплины подчиненными; количество случаев «нештатных ситуаций», произошедших из-за несоблюдения норм пожарной безопасности и охраны труда. Два последних показателя характеризуют не столько управленческие решения менеджеров низшего звена управления, сколько их управленческую деятельность в целом. Однако так как обеспечение соблюдения трудовой, пожарной дисциплины подчиненных регулируется не только их должностными инструкциями, но и решениями руководителя, то неисполнение ими общепринятых норм отрицательно характеризует деятельность руководителя. По мере перемещения прав разработки и реализации решений к уровню среднего звена управления возрастает и доля решений тактического характера, разрабатываемых и принимаемых менеджерами относительно самостоятельно. Достаточно часто от вышестоящего руководства поступают только задание и цель решения, а способы и средства достижения цели определяются менеджерами самостоятельно. Здесь возможно принятие решений с вероятностным результатом с применением эвристических методов обработки информации. На этом уровне власти качество решений оценивается по следующим показателям: доля решений, реализованных в установленные сроки; доля решений, реализованных с допустимым отклонением от ожидаемого результата; доля самостоятельно разработанных и реализованных решений; доля уникальных решений; среднее число критериев, принимаемых во внимание при разработке решений; доля времени на разработку решения в общем времени разработки и исполнения решения; доля решений, принятых коллегиально.

Руководители высшего звена управления занимаются в основном разработкой стратегических решений, направленных на достижение генеральной цели компании. Так, генеральный директор ответственен за определение путей развития предприятия, тенденций развития отдельных направлений деятельности, изыскание возможностей выхода на мировой рынок и т. д. О качестве решений, принятых руководителями высшего звена управления, можно судить на основании следующих показателей: доля реализованных решений; доля решений, разработанных с привлечением экспертов; доля уникальных решений; доля импульсивных решений; доля 
рискованных решений, реализованных с положительным результатом; темпы роста выручки от реализации и чистой прибыли предприятия; темпы роста дивидендов и прочих выплат собственникам капитала; увеличение доли рынка. Приведенные показатели качества управленческих решений можно измерить с помощью самоконтроля со стороны руководителя и его внутренней оценки. Качество управленческого решения отражается на качестве производимой продукции, оказываемых услугах и выполняемых работах. Низкое качество управленческих решений приводит к материальным потерям, а если при этом ухудшается качество продукции, то портится репутация организации. Поэтому качественные решения являются основой эффективного управления организацией.

\section{Контрольные вопросы.}

1. Дайте определение качества управленческого решения.

2. Какие основные условия определяют качество управленческого решения?

3. Какие факторы оказывают влияние на качество управленческих решений?

4. Соблюдение каких требований обеспечивают качественное управленческое решение?

5. Какие существуют методологические подходы к формированию качества управленческих решений?

\section{Контрольные тесты.}

1. Качество управленческих решений - это:

1) эффективные условия функционирования организации;

2) степень соответствия управленческого решения требованиям (стандартам) организации; Степень соответствия выработанных теоретических рекомендаций по обоснованию иели и путей ее достижения той реальной проблеме, которая является предметом решения;

3) эффективность реализачии управленческого решения;

4) степень соответствия параметров выбранной альтернативы решения определенной системе характеристик объекта управления. 
2. Общее качество управленческого решения вычисляется как:

1) сумма значений качеств этапов, операчий, стадий, составляюших управленческое решение и последовательно выполняющзихся;

2) разница между значениями всех составляющих этапов, стадий и операций, выполняющихся последовательно;

3) произведение значений качеств всех составляющих этапов, стадий и операщий, выполняющихся последовательно;

4) производное значений качеств всех составляющих этапов, стадий и операций, выполняюшихся последовательно.

3. К элементам, влияющим на качество процесса разработки управленческого решения, относят:

1) личо, принимающее решение;

2) информация;

3) значения качеств составляющих этапов;

4) методы разработки управленческих решений.

4. Обоснованность, как условие качества управленческого решения означает:

1) знание объективных законов развития системы и конкретного объекта управления, применительно к которому принимается решение;

2) психологически следует быть готовым е тому, что может возникнуть стация, при которой необходимо изменить решение;

3) принятое решение должно соответствовать реальным условиям функционирования объекта;

4) решение должно приниматься лицом или органом, имеющим соответствующее законное основание его принимать.

5. Системность как условие качества управленческого решения включает в себя:

1) необходимость прогнозировать тенденции развития объекта управления;

2) логическую связь между целями и методами их достижения

3) единство подхода к решению разных проблем, связанных между собой;

4) накопление практического опьта. 
6. Практичность, как условие качества управленческого решения означает, что:

1) организачия должна располагать возможностями для реализачии управленческого решения в ограниченные сроки и при имеющчихся ресурсах;

2) время, затраченное на принятие и реализацию управленческого решения, должно соответствовать реальным условиям;

3) необходимо уделять особое внимание условиям сбора необходимой информачиин;

4) к разработке управленческого решения необходимо привлекать собственных специалистов в качестве консультантов.

7. К факторам качества управленческого решения ситуационного характера относят:

1) метод получения информации;

2) позищия;

3) моральные и правовые нормыл.

4) методика.

8. К факторам качества управленческого решения поведенческого характера относят:

1) квалификация;

2) личность руководителя;

3) анализ и прогноз;

4) научное предсказание. 


\section{ГЛава 6. КОНТРОЛЬ РЕАЛИЗАЦИИ УПРАВЛЕНЧЕСКИХ РЕШЕНИЙ}

Контроль как функция управления представляет собой процесс обеспечения достижения поставленных целей и, соответственно, реализации принятых управленческих решений. Процесс контроля - это, с одной стороны, процесс установления стандартов, определения фактически достигнутых результатов и их отклонения от нормы; с другой - процесс мониторинга хода выполнения управленческих решений и оценки достигнутых результатов. Результаты контроля являются основанием для корректировки ранее принятых решений при обнаружении значительных отклонений от намеченного хода реализации решения. Другими словами, контроль представляет собой процесс сравнения полученных результатов с запланированными и, в случае необходимости, проведения соответствующих корректирующих мероприятий. Неопределенность как неотъемлемая характеристика будущего является главным обоснованием контроля в процессе реализации управленческого решения. Контроль сопутствует всем этапам процесса принятия управленческого решения.

По этому признаку различают следующие основные виды контроля. Предварительный контроль осуществляется до начала мероприятий по разработке решения. Его целью является предупреждение наступления нежелательных результатов до момента их появления за счет разработки критериев оценки, отладки методики и регламента контролирующих действий. Предварительный контроль используется для раскрытия признаков и причин проблемы, анализа неопределенностей, формулировки ограничений и оценки альтернатив.

Текущий контроль реализуется непосредственно в ходе процесса реализации решения. Он осуществляется руководителем и основан на измерении и изучении фактических промежуточных результатов выполненной работы в условиях воздействия внутренних и внешних факторов.

Регулярный контроль работы исполнителей, обсуждение возникающих вопросов позволяют оперативно устранить текущие отклонения от намеченных планов и заранее скорректировать процесс решения проблемы. 
Корректирующий контроль направлен на уже совершенные действия и создавшуюся ситуацию. Он предназначен для корректировки ситуации, когда известны результаты реализации управленческого решения и они противоречат запланированным значениям. Главной целью является недопущение повтора аналогичных ситуаций в будущем.

Заключительный контроль выполняется после того, как принятое решение реализовано. Назначение - учет, измерение конечных результатов и сравнение их с запланированными, на основании чего может быть сделан вывод о степени достижения цели. Следует помнить, что заключительный контроль осуществляется тогда, когда уже нельзя поменять решение в случае неудачного исхода. Он выполняет следующие важные функции: формирование и заполнение базы данных по направлениям (цели и составляющие их задачи, начальные, промежуточные и конечные параметры деятельности, критерии оценки исходных показателей, набор корректирующих решений, результаты достижения целей при конкретных параметрах деятельности, набор решений, но нейтрализации побочных явлений); сбор статистических данных о специфике работы в конкретной сфере, позволяющий руководителю принимать более адекватные решения в сложных ситуациях; разработка инновационных технологий для совершенствования процесса реализации решения.

Существует два варианта контроля: по результатам и по упреждению. Контроль по результатам использует организационную, экономическую, техническую и правовую документацию. Осуществляется оценка отклонения фактического результата от запланированных значений. Такой вариант контроля целесообразно применять в процессах с небольшим временем цикла и при невысокой стоимости процесса разработки и реализации решения. Управленческое решение постепенно совершенствуется на основе предыдущих результатов реализации, с помощью корректировок и уточнений. Контроль по упреждению основывается на стандартах, нормax, правилах и может осуществляться до начала или в процессе разработки и реализации решения.

Контроллинг - направление в управленческой практике, которое включает административный, технологический контроль, ревизию и аудит. Административный контроль представляет собой постоянное наблюдение за процессом разработки и реализации 
управленческого решения, сроками и качеством. Технологический контроль - контроль используемых технологий, применяемых в процессе разработки и реализации решений. Ревизия - документальное фискальное обследование результатов реализации решения. Аудит - документальное исследование результатов реализации решения, определяющее уровень его соответствия определенным критериям. Между процессами принятия решений, планирования и контроля существует неразрывная связь, которая определяется предназначением, миссией и целями управляемой системы. Требования к контролю формируются руководством с участием всех заинтересованных сторон и регламентируют состав анализируемой информации, структуру отчетов и ответственность за сбор данных, анализ информации и принятие решений.

Разработка эффективной системы контроля подразумевает: тщательное планирование всех мероприятий, проведение которых необходимо для достижения целей; оценка ресурсов и времени, необходимых для выполнения намеченных планов; сопоставление достигнутых результатов и использованных ресурсов с учетом временных характеристик; корректировка планов по временным и материальным затратам, необходимым для выполнения оставшейся работы; периодическое сопоставление полученных результатов и затрат с планом и бюджетом.

Эффективная система контроля должна обладать четко отлаженными механизмами координации, коммуникации, свойствами гибкости, экономичности, своевременности. Процессы передачи информации являются основой эффективного контроля. Контроль эффективен настолько, насколько адекватна, своевременна и точна информация, на которой базируется система. Разработка управленческих решений, оценка результатов их реализации требуют эффективной информационной системы.

Сотрудникам должны быть известны требования, предъявляемые к заданию, чтобы они могли их выполнить и на их основе осуществлять самоконтроль. Часто неэффективная работа является следствием того, что руководитель не располагает реальной информацией. Для быстрой и эффективной обработки данных о результатах работы необходимо использовать современные информационно-коммуникационные технологии. Координация контроля важное условие его эффективности. Контроль является средством координации выполнения заданий различными подразделениями и 
служащими, способствующим концентрации работников на достижении общеорганизационных целей. Результаты деятельности любого учреждения не являются результатом деятельности какогонибудь одного работника или отдела, а кроме того, задачи разных отделов или работников зачастую не взаимосвязаны.

Своевременность контроля заключается в том, что он должен проводиться именно тогда, когда это необходимо. Систематическое наблюдение за результатами позволяет принимать корректирующие меры в процессе реализации решения и достичь намеченных целей. В случае обнаружения каких-либо отклонений от намеченного плана работ принимают меры по их исправлению или устранению. Однако чрезмерный контроль или бесконечные проверки снижают эффективность и увеличивают сроки реализации управленческого решения. Гибкость системы контроля выражается в том, что в процессе реализации управленческого решения должны меняться как стандарты, так и возможные корректирующие действия. Контроль должен обладать характеристикой экономичности. Экономичность контроля. Если затраты на контроль превосходят создаваемые им преимущества, то следует от него отказаться. Иными словами, преимущества от контроля должны превосходить затраты финансовых, временных и человеческих ресурсов на его проведение.

Система контроля должна срабатывать только при наличии заметных отклонений фактических результатов от плановых значений. Четко структурированные планы являются основой контроля. При достаточно частом обновлении плана без применения процедуры контроля изменений контроль над реализацией решения может быть утрачен. При осуществлении контроля должна быть эффективная система отчетности. Необходимо основываться на единых подходах и критериях при формировании отчетов о ходе выполнения работ. Методика их подготовки и получения должна быть ясно определена и достаточно проста. Для всех видов отчетов необходимо определить четкие временные интервалы. Система анализа фактических показателей и тенденций позволяет установить, соответствует ли текущая ситуация запланированной, и, если нет, определить серьезность последствий выявленных отклонений.

Процесс контроля ориентирован на повышение вероятности достижения цели. В теории управления процессы принятия решений и контроля определяют как тесно взаимосвязанные, поэтому еще 
на стадии планирования следует разработать способ соотнесения планов с реальной ситуацией. Определение целей является не только частью процесса планирования, но и началом процесса контроля. Процесс контроля характеризуется следующим: содержательная составляющая определяет, что выполняется; организационная - кем и в какой последовательности осуществляется контроль; технологическая отвечает на вопрос, какие методики и технологии используются.

Целью контроля является обеспечение соответствия утвержденного решения и процесса его исполнения, предотвращение вероятных недоработок и проблем, выявление отклонений от заданной программы, поставленных целей и задач, установленных сроков. Содержание контроля раскрывают реализуемые им функции: диагностика состояния дел, ориентирование, стимулирование, корректировка действий, распространение опыта, осуществление надзора. Функция диагностики заключается в выявлении фактического состояния дел; ориентирующая функция сосредоточена на указании проблем, которые в данный момент заслуживают наибольшего внимания; стимулирующая направлена на выявление и вовлечение в работу всех временных, денежных, человеческих ресурсов.

В процессе реализации управленческого решения при сравнении фактических и запланированных результатов руководителю необходимо определить, насколько фактические результаты соответствуют установленным стандартам. Если выявлены явные расхождения, он должен решить, насколько они допустимы. Далее руководитель оценивает фактические результаты, т. е. делает вывод о качестве принятого решения. Деятельность на этой стадии процесса контроля связана с проведением следующих мероприятий: установление масштаба допустимых отклонений, оценка фактических результатов, информирование о результатах, оценка результатов.

В процессе реализации управленческого решения иногда допускается неточное соблюдение критериев выбора. Так, по отдельным характеристикам определяется интервал допустимых отклонений, в пределах которого они считаются несущественными. Размер интервала играет крайне важную роль. При достаточно большом интервале возможные отклонения приводят к необратимым последствиям. Если интервал мал, то руководитель будет реагировать на каждое незначительное отклонение, что требует больших финансовых и временных затрат, и контроль становится неэффективным. 
Особое внимание следует обратить на методику измерения фактических результатов, получаемых в процессе реализации решений. Важно корректно определить типы шкал, единицы измерения значений контролируемых параметров, выбрать частоту и точность измерений. Передача информации играет важную роль в процессе контроля. Ценность данных значительно снижается, если они несвоевременны и неточны. К информации предъявляется требование наглядности, что позволяет легко понимать смысл контролируемых процессов и предпринимать адекватные действия. Перечислим основные трудности, связанные с передачей информации: искажение сообщений в процессе межличностного общения и при прохождении по каналам передачи информации; информационные перегрузки, которые подавляют восприятие и мышление руководителя, занятого обработкой больших объемов информации; сложная организационная структура, затрудняющая прохождение информации и повышающая вероятность ее искажения. Оценка результатов заключается в сравнении фактических и требуемых результатов решения с учетом масштаба допустимых отклонений. На основании сравнения судят о том, достигнута ли цель принятия решения или нет. Если обнаруживаются существенные отклонения реальных значений показателей от плановых, принимается решение о выполнении корректирующих действий.

Итак, после оценки результатов реализации решения руководитель может выбрать одну из следующих стратегий: если результаты сравнения фактических и плановых значений позволяют сделать вывод, что цель достигнута, то никакие дополнительные действия не предпринимаются, а положительный опыт решения сохраняется в базе данных для использования в подобных ситуациях в будущем; если отклонения от намеченных результатов становятся недопустимыми, предпринимается попытка разобраться в причинах этих отклонений и предпринимаются необходимые мероприятия для возвращения на правильную траекторию. Если выявлены отклонения в ходе текущего контроля, то руководитель выполняет корректирующие действия непосредственно в процессе реализации решения. Если отклонения от цели обнаружены по результатам заключительного контроля, то проводится анализ новой проблемной ситуации и повторяется процесс разработки и реализации решения; несовпадение фактических и запланированных результатов 
объясняется тем, что была запланирована нереалистичная цель. Завышенные требования к качеству решений сводят на нет усилия исполнителей, снижают их мотивацию. И наоборот, легкость достижения поставленной цели объясняется слишком мягкими критериями выбора. Контрольная информация позволяет выявить необходимость доработки не только самих решений, но и требований, предъявляемых к их качеству, как в сторону повышения, так и в сторону понижения. Необходимо отметить, что при организации контроля необходимо учитывать следующее: реализацию контрольных функций следует поручать лицам, компетентным в данных вопросах, чтобы они могли быть способны оценить причины и следствия возможных отклонений и предложить мероприятия по их устранению; для обеспечения объективности и принципиальности оценок лица, отвечающие за контроль, не должны быть связаны материальными интересами с подконтрольными подразделениями.

Поскольку система контроля оказывает влияние на людей, при ее реализации руководитель должен учитывать следующие аспекты: люди негативно воспринимают внешний контроль; контроль определяет положение и власть того, кто его осуществляет; установки и стандарты могут быть по-разному поняты, и контроль может привести к конфликту между сотрудниками; при очень жестком контроле может быть ограничена гибкость системы, а нехватка гибкости и инициативы приводит к снижению уровня мотивации и способности к адаптации во внешней среде. Разработанные стандарты контроля должны быть осмыслены и восприняты всеми сотрудниками, чтобы каждый понимал причины и ожидаемые результаты, а участие в разработке и внедрении системы контроля поможет во многом преодолеть негативное отношение к ней. В процессе проведения контроля можно столкнуться со следующими трудностями: сложно избежать предвзятости и субъективных толкований; доверчивость, поверхностные наблюдения, стремление оправдать ожидания руководства; низкая компетентность; малые сроки для проведения детального анализа; отсутствие решимости сказать правду. Таким образом, контроль в первую очередь призван информировать исполнителей о ходе работы, ее соответствии планам руководителя. Сотрудник, реализующий управленческое решение, заинтересован в том, чтобы его усилия были замечены окружающими и оценены по достоинству. Так что иногда мягкий контроль повышает вес выполняемых исполнителем поручений, 
прибавляет самоуважения, уверенности. Для повышения эффективности контроля при его проведении следует учитывать следующие психологические факторы: увлеченно работающего сотрудника не стоит отвлекать, так как он примет контроль как помеху; контроль следует проводить, когда сотрудник испытывает сомнения или когда выполнен некоторый этап работы и он сам готов поделиться результатами; часто контролируемые задачи становятся более приоритетными для исполнителя по сравнению с менее контролируемыми, поэтому проводить контроль следует системно. В процедуре контроля есть три четко различимых этапа: установление плановых величин и критериев; сопоставление с ними реальных результатов; принятие необходимых корректирующих действий. На каждом этапе реализуется комплекс различных мер. Первый этап демонстрирует, насколько близки функции контроля и планирования. Плановые величины - это конкретные цели, прогресс в отношении которых поддается измерению. Эти цели явным образом связаны с процессом планирования. Цели, которые могут быть использованы в качестве плановых величин для контроля, отличают две очень важные особенности. Они характеризуются наличием временных рамок, в которые должна быть выполнена работа, и конкретного критерия, по отношению к которому можно оценить степень выполнения работы. Показатели результативности точно определяют, что необходимо для достижения поставленных целей. Подобные показатели позволяют руководству сопоставить реально сделанную работу с запланированной и ответить на следующие важные вопросы: что мы должны сделать, чтобы достичь запланированных целей, что осталось не сделанным? Невозможность выразить показатель результативности непосредственно в количественной форме не должна служить оправданием (а зачастую именно так и бывает) того, чтобы не устанавливать плановых величин в этой области вообще. Даже субъективный показатель, при условии, что осознается его ограниченность, лучше, чем ничего. Руководство не может эффективно осуществлять контроль без показателя результативности какого-либо типа. Второй этап процесса контроля состоит в сопоставлении реально достигнутых результатов с установленными плановыми. На этом этапе менеджер должен определить, насколько достигнутые результаты соответствуют его ожиданиям и насколько допустимы или относительно безопасны обнаруженные отклонения от планов. На этой 
стадии процедуры контроля дается оценка, которая служит основой для решения о начале действий. Деятельность, осуществляемая на этой стадии контроля, зачастую наиболее заметная часть всей системы контроля. Эта деятельность заключается в определении величины отклонений, измерении результатов, передаче информации и ее оценке. Если принята слишком большая величина допустимых отклонений, то руководство может пропустить достаточно крупные проблемы. Но если принятая величина слишком мала, то организация будет реагировать на очень небольшие отклонения, что весьма разорительно и требует много времени. Такая система контроля может парализовать и дезорганизовать работу организации и будет скорее препятствовать, чем помогать достижению целей организации. В подобных ситуациях достигается высокая степень контроля, но процесс контроля становится неэффективным. Для того чтобы быть эффективным, контроль должен быть экономным. Преимущества системы контроля должны перевешивать затраты на ее функционирование. Затраты на систему контроля состоят из затрат времени, расходуемого менеджерами и другими работниками на сбор, передачу и анализ информации, а также из затрат на все виды оборудования, используемого для осуществления контроля, и затрат на хранение, передачу и поиск информации, связанной с вопросами контроля. Измерение результатов позволяющих установить, насколько удалось соблюсти установленные планы, - это самый трудный и самый дорогостоящий элемент контроля. Для того чтобы быть эффективной, система измерения должна соответствовать тому виду деятельности, который подвергается контролю. Вначале необходимо выбрать единицу измерения, причем такую, которую можно преобразовать в те единицы, в которых выражены плановые величины. Так, если установленная плановая величина - это прибыль, то измерение следует вести в рублях или процентах в зависимости от формы выражения плановой величины. Выбор подходящей единицы измерения - это зачастую наиболее легкая часть проведения контрольных измерений. Равно важно, чтобы скорость, частота и точность измерений тоже были согласованы с деятельностью, подлежащей контролю. Любая система сбора и обработки информации относительно дорога. Стоимость проведения измерений зачастую наиболее крупный элемент затрат во всем процессе контроля. Часто именно этот фактор 
определяет, стоит ли вообще осуществлять контроль. Из-за высокой стоимости измерений, в частности, менеджер должен избегать искушения измерить все и как можно точнее. Если проводить измерения подобным образом, то затраты на систему контроля будут столь велики, что ее стоимость превзойдет возможные доходы от ее применения. Тем более что в коммерческой деятельности цель проведения измерений состоит в увеличении прибыли, а не в том, чтобы точно установить, что же происходит на самом деле. Для того чтобы система контроля действовала эффективно, необходимо обязательно доводить до сведения соответствующих работников организации как установленные плановые величины, так и достигнутые результаты. Подобная информация должна быть точной, поступать вовремя и доводиться до сведения ответственных за соответствующий участок работников в виде, легко позволяющем принять необходимые решения и выполнить нужные действия. Желательно также быть полностью уверенным, что установленные плановые величины хорошо поняты сотрудниками. Это означает, что должна быть обеспечена эффективная связь между теми, кто устанавливает плановые величины, и теми, кто должен их выполнять. Основные трудности, возникающие на пути сбора и распространения контрольной информации, связаны с различными коммуникационными проблемами. Искажения информации могут сыграть очень значительную роль в тех случаях, когда неизбежны субъективные оценки.

Менеджер должен решить, нужная ли, информация получена и важна ли она. Важная информация - это информация, которая адекватно описывает исследуемое явление и существенно необходима для принятия правильного решения. Иногда оценка информации определяется политикой организации. При этом менеджер должен принимать в расчет риск и другие факторы, определяющие выбор того или иного решения. Цель этой оценки состоит в том, чтобы принять решение: необходимо ли действовать, и если да, то как. После вынесения оценки процесс контроля переходит на третий этап. Менеджер должен выбрать одну из трех линий поведения: ничего не предпринимать, устранить отклонение или пересмотреть стандарт. Основная цель контроля состоит в том, чтобы добиться такого положения, при котором процесс управления организацией действительно заставлял бы ее функционировать в соответствии с 
планом. Если сопоставление фактических результатов с плановыми говорит о том, что установленные цели достигаются, лучше всего ничего не предпринимать. В управлении нельзя, однако, рассчитывать на то, что случившееся один раз повторится снова. Даже наиболее совершенные методы должны подвергаться изменениям. Так, например, если система контроля показала, что в каком-то элементе организации все идет хорошо, необходимо продолжать измерять результаты, повторяя цикл контроля. Система контроля, которая не позволяет устранить серьезные отклонения прежде, чем они перерастут в крупные проблемы, бессмысленна. Естественно, что проводимая корректировка должна концентрироваться на устранении настоящей причины отклонения. В идеале стадия измерений должна показывать масштаб отклонения от плановой величины и точно указывать его причину. Это сопряжено с необходимостью эффективной процедуры принятия решений. Однако, поскольку большая часть работы в организации - это результат объединенных усилий групп людей, то абсолютно точно определить корни той или иной проблемы не всегда представляется возможным. Смысл корректировки во всех случаях состоит в том, чтобы понять причины отклонения и добиться возвращения к правильному образу действий. Осуществление корректировки может быть достигнуто путем улучшения значения каких-либо внутренних переменных факторов данной организации, усовершенствования функций управления или технологических процессов. Важно подчеркнуть, что причиной возникающих проблем может быть любая переменная величина и что вклад в отклонение полученных результатов от желаемых может давать сочетание различных факторов. Естественно, менеджер не может выбрать какое-то одно корректирующее действие только потому, что оно решает только что возникшую проблему. Прежде чем выбирать корректирующее действие, необходимо взвесить все имеющие отношения к данной проблеме внутренние переменные и их взаимосвязи. Поскольку все подразделения организации так или иначе связаны между собой, любое крупное изменение в одном из них затронет всю организацию. Вот почему менеджер должен вначале убедиться, что предпринимаемое им корректирующее действие не создаст дополнительных трудностей, а поможет их разрешить. Кроме того, хотя временами это может быть очень трудно, опытный менеджер дол- 
жен избегать решений, которые в краткосрочном плане сулят преимущества, однако в долгосрочном влекут за собой большие затраты. Не все заметные отклонения от плановых величин следует устранять. Иногда сами плановые величины могут оказаться нереальными, потому что они основываются на планах, а планы - это лишь прогнозы будущего. При пересмотре планов должны пересматриваться и плановые величины. Успешно действующие организации зачастую вынуждены пересматривать свои плановые величины в сторону повышения. Кроме того, временами оказывается, хотя это и не должно происходить слишком часто, что планы составлены чересчур оптимистично. Поэтому плановые величины подчас надо пересматривать и в сторону понижения. Следует помнить, что плановые величины, достичь которых очень трудно, фактически делают тщетными стремления рабочих и менеджеров достичь сформулированных целей и сводят на нет всю мотивацию. Как и в случае с корректирующими действиями различного типа, необходимость радикального пересмотра плановых величин (в сторону повышения или понижения) может служить симптомом проблем, возникших либо в процессе собственно контроля, либо в процессе планирования.

Для того чтобы контроль мог выполнить свою истинную задачу, т.е. обеспечить достижение целей организации, он должен соответствовать нескольким важным требованиям. Стратегическая направленность. Контроль должен отражать общие приоритеты организации и поддерживать их. Относительная сложность оценки какого-либо вида деятельности в количественном виде или измерения ее результативности по принципу затраты (эффект никогда не должен служить критерием для решения, нужно ли вводить механизм контроля). Деятельность в областях, которые не имеют стратегического значения, следует измерять не очень часто, а о полученных результатах можно никому не сообщать до тех пор, пока отклонения не станут необычно большими. Абсолютный контроль над обычными операциями (такими как мелкие расходы) не имеет смысла и будет только отвлекать силы от более важных целей. Но если высшее руководство считает, что какие-то виды деятельности имеют стратегическое значение, то в каждой такой области обязательно должен быть налажен эффективный контроль, даже если эта деятельность с трудом поддается измерению. Естественно, что 
стратегические области в разных организациях будут разными, но все организации нуждаются в эффективных системах контроля.

Ориентация на результаты. Конечная цель контроля состоит не в том, чтобы собрать информацию, установить стандарты и выявить проблемы, а в том, чтобы решить задачи, стоящие перед организацией. Проведение измерений и оповещение об их результатах важно только как инструмент для достижения этой цели. Необходимо тщательно следить за тем, чтобы средства контроля не заняли более важного места, чем подлинные цели организации. Бесполезно иметь обширную и точную информацию о различных отклонениях от намеченных целей, если эта информация не используется для осуществления корректирующих действий. Это означает, что информация о результатах контроля важна только тогда, когда доходит до лиц, обладающих правом произвести на ее основании соответствующие изменения. Когда контрольный механизм не срабатывает, причина чаще всего кроется в том, что необходимо усовершенствовать структуру прав и обязанностей, а не процедуру измерений. Таким образом, чтобы быть эффективным, контроль должен быть интегрирован с другими функциями управления. В итоге контроль можно назвать эффективным только тогда, когда организация фактически достигает желаемых целей и в состоянии сформулировать новые цели, которые обеспечат ее выживание в будущем. Соответствие контролируемому виду деятельности. Для того чтобы быть эффективным, контроль должен соответствовать контролируемому виду деятельности. Он должен объективно измерять и оценивать то, что действительно важно. Неподходящий механизм контроля может скорее маскировать, а не собирать критически важную информацию. Своевременность. Для того чтобы быть эффективным, контроль должен быть своевременным. Своевременность контроля заключается не в исключительно высокой скорости или частоте его проведения, а во временном интервале между проведением измерений или оценок, который адекватно соответствует контролируемому явлению. Значение наиболее подходящего временного интервала такого рода определяется с учетом временных рамок основного плана, скорости изменений, а также затрат на проведение измерений и распространение полученных результатов. Система эффективного контроля - это система, которая дает нужную информацию нужным людям до того, как разовьется кризис. 
Гибкость. Контроль, как и планы, должен быть достаточно гибким и приспосабливаться к происходящим изменениям. Незначительные изменения планов редко бывают сопряжены с необходимостью серьезных изменений в системе контроля. Так, например, фирма, производящая 100 различных товаров, должна использовать методы контроля запасов с тем, чтобы контролировать любое относительно большое увеличение или уменьшение количества товаров, а также количество каждого из видов товара, имеющегося в данный момент времени. Без достаточной (и весьма значительной) степени гибкости система контроля будет не действенна в тех ситуациях, для которых она предназначалась. Простота. Как правило, наиболее эффективный контроль - это простейший контроль с точки зрения тех целей, для которых он предназначен. Простейшие методы контроля требуют меньших усилий и более экономичны. Но самое важное состоит в том, что, если система контроля слишком сложна и люди, взаимодействующие с ней, не понимают и не поддерживают ее, она не может быть эффективной. Избыточная сложность контроля ведет к беспорядку, который можно назвать синонимом потери контроля над ситуацией. Для того чтобы быть эффективным, контроль должен соответствовать потребностям и возможностям людей, взаимодействующих с системой контроля и реализующих ее. Экономичность. Очень редко при помощи контроля стремятся достичь полного совершенства в работе организации, поскольку прогрессирующие усовершенствования и улучшения на последних этапах требуют непропорционально больших затрат усилий и средств. Никогда не следует забывать, что все затраты, совершаемые организацией, должны приводить к увеличению ее преимуществ и доходов. Затраты средств должны приближать организацию к поставленным целям. Таким образом, если суммарные затраты на систему контроля превосходят создаваемые ею преимущества, организации лучше не использовать эту систему контроля вообще или же ввести менее тщательный контроль. Вообще, поскольку в контроле скрыто много побочных затрат, таких как затраты рабочего времени и отвлечение ресурсов, которые могли бы быть затрачены на решение других задач, то для того, чтобы контроль был экономически оправдан, отношение затрат к возможной прибыли у него должно быть довольно низким. Конечно, для того чтобы определить реальное соотношение затрат и 
прибыли для системы контроля, необходимо рассматривать как долгосрочные, так и краткосрочные аспекты.

Контроль на международном уровне. Когда организации осуществляют свой бизнес на зарубежных рынках, функция контроля приобретает дополнительную степень сложности. Поскольку при выходе на международный уровень количество целей в предпринимательской деятельности значительно увеличивается, то контроль в этом случае осуществлять труднее. Менеджеры должны не только устанавливать стандарты, измерять результативность и предпринимать корректирующие действия для своего бизнеса внутри страны, но и осуществлять аналогичные операции для своего международного бизнеса. Очевидно, что чем более глобален их бизнес, тем труднее осуществлять функцию контроля. Дополнительный фактор, осложняющий ситуацию с контролем, связан с возможными коммуникационными проблемами, возникающими между центральной штаб-квартирой корпорации и ее филиалами и дочерними фирмами. Подобные проблемы могут возникать из-за географической удаленности, языковых и культурных барьеров. Менеджерам, которые столкнулись с проблемами при решении этих задач на международном уровне, можно воспользоваться следующими приемами: периодически проводить совещания в штабквартире фирмы с соответствующим персоналом зарубежных отделений и филиалов; осуществлять визиты руководства центрального офиса корпорации в зарубежные филиалы и дочерние компании; назначать на работу в зарубежные филиалы менеджеров из центральной штаб-квартиры; требовать предоставления отчетов из зарубежных отделений в штаб-квартиру фирмы с детальным описанием результатов деятельности по отдельным направлениям работ; осуществлять различные виды бюджетно-финансового контроля.

Помимо рассмотренных выше инструментов контроля, таких как использование обратной связи, установление правил и процедур, существуют инструменты контроля, основанные на учете особенностей поведения персонала, т.е. тех людей, которые осуществляют реализацию принятого управленческого решения. Учет особенностей поведения персонала: установление осмысленных стандартов, воспринимаемых сотрудниками. Люди должны чувствовать, что стандарты, используемые для оценки их деятельности, 
действительно достаточно полно и объективно отражают их работу. Кроме того, они должны понимать, чем и как они помогают своей организации в достижении ее интегральных целей. Если сотрудники видят, что установленные стандарты контроля не полны и не объективны или же попросту «ловят блох», то они могут игнорировать их или сознательно нарушать либо будут испытывать усталость и разочарование. Менеджеры должны также стремиться к тому, чтобы установленные ими стандарты были бы искренне восприняты и одобрены теми людьми, чью деятельность они будут определять. Иногда для повышения приемлемости стандартов необходимо, чтобы работники сами принимали участие в их разработке; установление двустороннего общения - в случае возникновения каких-либо проблем с системой контроля у подчиненного должна быть возможность открыто обсудить их, не опасаясь, что руководство обидится на это. Подобное общение должно способствовать точному пониманию работниками истинной цели контроля и помогать установить скрытые упущения в системе контроля, неочевидные для ее создателей из высшего руководства фирмы; избежание чрезмерного контроля - нельзя перегружать своих подчиненных многочисленными формами контроля, иначе это будет поглощать все их внимание и приведет к полному беспорядку и краху. Основной вопрос, который надо задавать при введении того или иного типа контроля, следующий: необходимо ли это для того, чтобы предотвратить или предупредить значительные отклонения от желаемых результатов? Кроме того, конторолеры-руководители не должны проверять работу чаще и тщательнее, чем это необходимо. Иначе, по понятным причинам, это может просто раздражать; установление жестких, но достижимых стандартов при разработке мер контроля важно принять во внимание мотивацию. Четкий и ясный стандарт часто создает мотивацию уже тем, что точно говорит работникам, чего ждет от них организация. Однако согласно мотивационной теории ожидания можно мотивировать людей на работу для достижения только тех целей, которые они склонны считать реальными. Таким образом, если стандарт воспринимается как нереальный или несправедливо высокий, то он может разрушить мотивы работников. Аналогично, если стандарт установлен на столь низком уровне, что достичь его не составляет никакого труда, это обстоятельство может оказывать демотивиру- 
ющее воздействие на людей с высоким уровнем потребностей в достижении результатов. Хороший менеджер чувствует разницу в потребностях и возможностях подчиненных и устанавливает стандарты с учетом этих различий; вознаграждение за достижение результата - согласно теории ожидания существует четкая взаимосвязь между результативностью и вознаграждением. Если руководство организации хочет, чтобы сотрудники были мотивированы на полную самоотдачу в интересах организации, оно должно справедливо вознаграждать их за достижение установленных стандартов результативности. Если работники не ощущают такой связи или чувствуют, что вознаграждение несправедливо, то их производительность в будущем может упасть.

Появление контроллинга связано с необходимостью принятия решений в условиях динамичности рыночных отношений. Контроллинг - это концепция, направленная на ликвидацию узких мест и ориентированная на будущее в соответствии с поставленными целями и задачами, т.е. это управление будущим для обеспечения длительного и эффективного функционирования предприятия и его структурных единиц. Основные задачи контроллинга - выявление проблем и корректировка деятельности предприятия для предупреждения кризиса, контроль и регулирование, а также информационное сопровождение процесса планирования. Стратегический контроллинг призван оказывать помощь менеджерам в принятии решений по эффективному использованию преимуществ предприятия и созданию новых потенциалов успешной деятельности в перспективе. Служба стратегического контроллинга выступает в качестве внутреннего консультанта менеджеров и собственников компании при разработке стратегии, стратегических целей и задач. Она поставляет информацию, необходимую руководству в процессе принятия и реализации решения. К основным методам контроля реализации решений в рамках стратегического контроллинга можно отнести портфельный анализ, анализ потенциала, анализ кривой опыта, анализ сильных и слабых сторон, стратегических разрывов, метод сценариев и т.п. Основная задача текущего контроллинга - оказывать помощь менеджерам в принятии решений по достижению запланированных целей, которые выражаются чаще всего в виде количественных значений уровней рентабельности, ликвидности и прибыли. Текущий контроллинг ориентирован 
на краткосрочный результат. К методам контроля реализации решений в рамках текущего контроллинга можно отнести ABC-анализ, анализ объема заказов, анализ величин в точке безубыточности, метод расчета сумм покрытия, анализ узких мест, анализ отклонений и др.

Таким образом, для эффективной реализации управленческих решений и получения запланированных результатов менеджеру необходимо осуществлять контроль выполнения принятых решений. В этих условиях требуется комплексная методология и основанный на ней инструментарий, которые бы позволили предопределить стабильные успехи в настоящем и будущем. В качестве такого инструмента выступает контроллинг, который призван оказывать помощь менеджерам в процессе разработки, принятия и реализации управленческих решений.

\section{Контрольные вопросы.}

1. В чем проявляется контроль реализации управленческих решений?

2. В чем заключается технология организации выполнения управленческих решений?

3. Чем обусловлено появление контроллинга?

4. Какие выделяют инструменты контроля?

\section{Контрольные тесты:}

1. Задачей контроля, как управленческой деятельности является:

1) качественная оценка результатов работы организации;

2) проверка всех сторон деятельности организачии;

3) количественная оченка результатов работы организации;

4) качественная и количественная оценка и учет результатов работы организации.

2. Для доведения до подчиненных решений, в которых четко определены все параметры решения, рекомендуется проводить:

1) заседания;

2) наставление;

3) сообщение;

4) совет. 
3. При принятии решений, средства и методы исполнения которых строго не регламентированы и оставлены на усмотрение исполнителей рекомендуется проводить:

1) инструктирование;

2) совещчание;

3) принуждение;

4) предписание.

4. В зависимости от времени контроля выделяют:

1) предварительный;

2) текущзии;

3) реализационныли;

4) направленный.

5. По периодичности выполнения контрольных операций выделяют контроль:

1) непрерывный;

2) периодическии;

3) ичиклический;

4) равномерный.

6. Корректирующий контроль направлен на:

1) уже совершеннье действия и создавшуюся ситуачию;

2) измерение конечных результатов;

3) измерение изучение фактических промежуточных результатов;

4) предупреждение наступления нежелательных результатов.

7. Какие принципы необходимо соблюдать, чтобы минимизировать отрицательные психологические последствия контроля:

1) объектами контроля должны быть явления и процессы в полном, как можно более широком объеме;

2) как можно шире использовать публичню оценку деятельности сотрудников, имеющих недочеты в работе;

3) контроль должен осуществляться систематически, что позволит на ранней стации выявить негативнье моменть;;

4) не контролировать всех сотрудников, принимающих участие в реализации решения, а только вызывающих сомнение.

8. К причинам отклонений при реализации управленческого решения относятся:

1) ошибка руководителя при выборе путей решения;

2) сознательное сопротивление группь исполнителей;

3) сознательное сопротивление руководителя;

4) недостаток информации. 
9. Существуют два варианта контроля:

1) по результатам;

2) по упреждению;

3) по направлениям;

4) структурныци.

10. Контроллинг включает в себя:

1) административный и технологический контроль;

2) ревизию;

3) aудит;

4) финансовый контроль.

11. К формам процесса контроля при реализации управленческих решений относят:

1) мониторинг;

2) измерение;

3) анализ;

4) отклонение.

12. Если выявленные отклонения превышают заранее определенную норму, то проводиться:

1) корректировка;

2) измерение;

3) мониторинг;

4) контроль. 


\section{ГЛАВа 7. ИНСТРУМЕНТЫ И ХАРАКТЕРИСТИКИ ЭФФЕКТИВНОГО КОНТРОЛЯ РЕАЛИЗАЦИИ УПРАВЛЕНЧЕСКИХ РЕШЕНИЙ}

Специалисты в области менеджмента выделяют два аспекта эффективности управленческих решений. Целевой аспект отражает меру достижения целей организации, а затратный - экономичность способов преобразования ресурсов в результаты производства. Выявление целей и образа действий для их достижения является предметом стратегического планирования. Выбор же технологий преобразований ресурсов в заданные результаты представляет собой тактическую задачу. В связи с этим правомерно целевую эффективность назвать стратегической, а затратную - тактической. Исследование названного понятия в связке с тактической эффективностью означает группировку соответствующих показателей по признаку, адекватному природе управленческих решений. Это дает возможность более четко определить области их применения. Эффективное решение (или эффективный выбор) не означает сведение оценок эффективности деятельности предприятий лишь к одной - отношению результата к затратам. На деле это означает игнорирование критериев принятия стратегических решений, от которых зависит их качество.

Для того чтобы быть эффективным, управленческое решение должно удовлетворять следующим требованиям: быть устойчивым по эффективности к возможным ошибкам в определении исходных данных; быть реальным, т. е. исходить из достижимых целей, располагаемых реально времени и ресурсов; содержать механизмы реализации это означает, что содержание решения включает в себя разделы, охватывающие организацию, контроль при реализации решении; быть реализуемым, т. е. не содержать положений, срывающих исполнение в результате определенных конфликтов; готовиться, приниматься и выполняться в реальном масштабе времени тех процессов, которыми управляют, учитывая возможные скорости развития нештатных ситуаций; быть гибким, т.е. изменить цель или алгоритм достижения цели при изменении внутренних и внешних условий, содержать описание состояний объекта управления, внешней среды, при которых выполнение решений должно быть приостановлено и начата разработка нового решения; предусматривать возможность контроля исполнения. 
Эффективность деятельности предприятия в целом зависит: от качества целеполагания, т. е. соответствия планируемых целей требованиям внешней среды, возможностям предприятия и интересам персонала; силы и направленности мотиваций, побуждающих членов организации к достижению целей; адекватности выбранных стратегий поставленным целям; объема и качества вовлекаемых в производство ресурсов (тактический аспект эффективности).

Однако целевой и затратный принципы эффективного решения, по мнению многих авторов, не являются единственными критериями определения эффективности управленческого решения. Некоторые авторы считают, что в реальных задачах принятия решений к этапу выбора все еще сохраняется большая неопределенность информации, обусловленная наличием многих ситуаций и целей. В связи с этим сразу осуществить выбор единственного решения из множества сформулированных очень сложно, поэтому используется принцип последовательного уменьшения неопределенности, заключающийся в последовательном сужении множества решений (альтернатив). Множество альтернативных решений сужается до множества допустимых решений на основе учета ограничений. Приемлемыми, или допустимыми, называют решения, удовлетворяющие множеству ограничений. Процедура получения множества приемлемых решений из исходного множества может выполняться путем логического мышления или формально, в зависимости от степени формализации информации. Таким образом, сужение множества приемлемых решений до множества эффективных решений осуществляют на основе анализа предпочтений. Решение называется эффективным если не существует более предпочтительного. Множество эффективных решений в литературе называют также множеством Парето.

Все эффективные решения между собой несравнимы, т. е. нельзя сказать, какое из них предпочтительнее. В частных случаях множество эффективных решений может содержать только одно решение или совпадать с множеством допустимых решений. В первом случае единственное решение является оптимальным, а во втором случае сужение допустимого не произошло. Непосредственно из определения эффективных решений следует, что оптимальное решение содержится только в этом множестве, поэтому нахождение этого множества решений является необходимой процедурой в процессе выбора решений. При этом определение единственного 
оптимального решения из множества эффективных в силу несравнимости этих решений может быть осуществлено только с привлечением дополнительной информации. Если информацию получить невозможно или ее получение нерационально вследствие ограниченности времени и больших затрат ресурсов, то лицо принимающее решение проводит неформальный анализ эффективных решений и определяет оптимальное решение, т.е. соотносит важность целей и различные положительные и отрицательные последствия решений. Определение множества эффективных решений составляет важный этап в последовательной процедуре выбора решений и основывается на использовании принципа Парето (сильная зависимость всех членов от группового лица принимающего решения, которая выражается в общности целей всех членов группы). Его можно использовать для всех классов группового и многокритериального выбора для нахождения эффективных решений. Как правило, применение этого принципа дает возможность определить не одно, а некоторое подмножество эффективных решений, поэтому понятие оптимального решения не обязательно означает единственное решение. Это в общем случае подмножество решений. В тех случаях, когда эффективное решение является единственным, оно является окончательным оптимальным решением.

Множество эффективных решений обладает следующими свойствами: любые два эффективных решения являются не доминирующими по отношению друг к другу; для любого решения, не принадлежащего множеству эффективных решений, всегда найдется по крайней мере одно эффективное решение, которое доминирует над ним.

Перечисленные свойства множества эффективных решений приводит к следствию: оптимальное решение находится среди эффективных решений. Таким образом, определив множество эффективных решений, достаточно в дальнейшем рассматривать только это множество для нахождения оптимального решения, отбросив все решения, не являющиеся эффективными. Однако не все эффективные решения являются строго лучшими, чем неэффективные. Какое-либо эффективное решение может быть эквивалентным некоторому неэффективному решению или несравнимым с ним. Однако в соответствии со вторым свойством во множестве эффективных решений найдется обязательно хотя бы одно лучшее решение для любого неэффективного решения. 
Эффективность решений - одно из важных понятий в теории принятия управленческого решения. Слово «эффект» означает впечатление, производимое кем-нибудь или чем-нибудь на кого-либо; действие как результат чего-нибудь, следствие чего-нибудь; средство, с помощью которого создается впечатление на кого-либо. Чтобы достичь эффекта, необходимо выбрать и реализовать конкретный способ проведения операции, т.е. определить конкретные активные средства, которые будут задействованы, объекты приложения усилий, а также условия (штатные) исполнения предписанных действий. Объектами приложения усилий в каждом из возможных способов могут быть принципиально только два: какие-то из физических (неодушевленных) объектов операции или субъекты операции. Эффект от воздействия по физическим объектам приводит к изменению их состояния (например, пятно от пролива нефтепродуктов из трюмов танкера может быть ликвидировано или не ликвидировано), нарушению связей между объектами, формы или качества элементов, входящих в систему, подвергающуюся воздействию.

Под эффективностью решения понимают степень полезности для лица принимающего решения предполагаемого (будущего) или действительно полученного в операции эффекта. Суждение об эффективности решения может быть вынесено лицом принимающем решения, например, в качественной шкале и отражать как минимум три градации предпочтительности ожидаемого или полученного эффекта: положительный эффект (полезный); нулевой эффект; отрицательный эффект (вредный).

Степень эффективности решений в рамках каждой из градаций может быть уточнена с использованием числовой (например, порядковой или балльной) шкалы, а иногда - количественной шкалы. Следовательно, эффективность решения предполагает субъективную оценку его качества, оценку, с точки зрения лица принимающего решения, полезности рассматриваемого решения для достижения цели операции. Такую оценку лицо принимающее решение выносит для себя перед ответственным моментом - принятием решения о том, какую из альтернатив в операции предпочесть. Именно эта оценка и является рациональной основой для осмысленного выбора. 
Однако каким бы опытным и искусным ни было лицо принимающее решение, оно никогда не застраховано от неудач в своей деятельности. Это давно уже считается аксиомой управления. Причин подобного пессимистического взгляда на реальности управления много, как объективных, так и субъективных. Объективные причины не зависят от личности человека и диктуются внешними обстоятельствами. Одной из наиболее веских объективных причин неудач в управлении следует считать рискованность, неопределенность «механизма ситуации». К субъективным причинам можно отнести рутинную проблему, когда у руководителя вырабатывается типовые методы ее решения; когда есть выбор, но недостаточно информации для принятия правильного решения или решение принимается импульсивно в силу настроения человека.

Руководитель всегда принимает решения, основываясь только на доступной ему в данный момент информации об обстановке. Однако информация о ситуации и сама ситуация - это далеко не одно и то же. Информация о ситуации - это упрощенный образ, ее модель. Как и всякая модель, информация о ситуации обладает ограниченной полнотой, точностью и своевременностью сведений и данных. Лицо, принимающее решение, всегда должно учитывать, что только решения и планы бывают идеальными, а люди и обстоятельства всегда реальны, и поэтому любое управленческое решение, любой план несет в себе возможность не только успеха, но и неудачи. Таким образом, правильнее говорить как бы о двух оценках эффективности решений: о теоретической (априорной) эффективности решения, на основе которой делается обоснованный выбор наилучшей альтернативы для реализации, и о фактической (апостериорной) эффективности решения.

В качестве основных исходов реализации какого-либо решения можно выделить лишь два: «Успех» и «Неудача». Поскольку эффективность решений для ЛПР определяется не только соотношением величин полезности успеха или тяжести неудачи, но и соотношением шансов на успех и неудачу, учитываются меры неопределенности. Различают объективные и субъективные факторы, которые влияют на исход операции. К объективным факторам относятся такие важные обстоятельства, как собственные экономические и технические возможности лица принимающего решения, обстоятельства, определяющие степень благоприятности для него 
экономической, политической и местной ситуации, наличие хороших и надежных партнеров. Субъективными факторами являются характеристики личности лица принимающего решения как управленца. Хороший управленец - это личность, стремящаяся к лидерству; это личность харизматическая, привлекающая людей, вдохновляющая их на действия, излучающая энергию и уверенность, порождающая у людей желание идти за ней.

Хороший управленец должен обладать способностью к беспристрастному анализу ситуации. Для этого в сложных ситуациях необходимо прибегать к использованию как качественных, так и количественных методов анализа решений. Эту способность можно назвать рассудительностью. Однако одной рассудительности мало. Многие люди обладают способностью провести глубокий анализ, сделать важные выводы из него. Многие могут длительное время изучать закономерности и взаимосвязи. Из такого типа людей получаются хорошие аналитики, эксперты, исполнители. Однако для того, чтобы стать настоящим руководителем (менеджером), лицо принимающее решение должно обладать и другими важными качествами личности.

Для повышения эффективности своих решений лицо принимающее решение должно иметь смелость, решительность, твердость в отстаивании и воплощении собственных идей и решений на практике. Совокупность этих качеств личности называется характером. Помимо этого, чтобы добиться успеха, необходимо обладать такими качествами, как предприимчивость и неустанный поиск нового (инициативность) и, конечно же, опытом. Это не только личный опыт лица принимающего решения, но и его способность обратиться к опыту других, умение окружить себя талантливыми людьми. Обобщая сказанное, можно утверждать, что шансы на «Успех» и сама степень успеха, несомненно, зависят от совершенствования деятельности объекта управления (финансовые показатели, объем реализации продукции, ее качество, уровень удовлетворения запросов потребителей и др.). Затраты на управление определяются затратами на основные фонды и содержание аппарата управления, затратами на приобретение и эксплуатацию информационно-технических средств управления и др. 


\section{Контрольные вопросы.}

1. В чем заключается эффективность управленческого решения?

2. В чем заключается механизм оценки экономической эффективности управленческого решения?

3. Какие существуют виды эффективности управленческого решения.

4. Какими качествами должно обладать лицо, принимающее решения для принятия эффективного управленческого решения?

\section{Контрольные тесты:}

1. Целевую эффективность управленческих решений называют:

1) стратегической;

2) тактической;

3) плановой;

4) затратной.

2. Эффективность управленческого решения это:

1) ресурсная результативность, полученная по итогам разработки или реализации управленческого решения в организаџии;

2) соотношение результата и затрат на какую-либо деятельHость;

3) достижение поставленной цели;

4) факт достижения определенных результатов.

3. Эффективность управленческого решения подразделяется на:

1) сочииальную;

2) технологическую;

3) управленческую;

4) рациональную.

4. К требованиям, обеспечивающим эффективность управленческого решения, относят:

1) маситабность;

2) реальность;

3) гибкость;

4) допустимым.

5. Эффективность управления складывается из:

1) эффективности организации;

2) эфффективности функционирования организации;

3) эффрективности работь руководителя;

4) эффективности работы элементов организации. 
6. Для оценки эффективности сравнивают:

1) альтернативы;

2) результат с затратами в сопоставимых показателях;

3) положительные и отрицательные результаты;

4) затратыл.

7. Между различными видами эффективности:

1) существуют зависимости и связи;

2) не существует связей;

3) не существует зависимостей;

4) существуют связи, но нет зависимостей.

8. Эффективность системы управления складывается из:

1) эффективности управленческих решений;

2) эффективности деятельности системь;

3) имиджа;

4) эффективности деятельности руководителя.

9.Экономическая эффективность определяется:

1) фактом достижения сочиильных изелей общества;

2) как соотношение финансовых преимуществ, полученных в результате реализации управленческого решения и затрат на его разработку и реализацию;

3) как соотношение финансовых затрат при реализации управленческих решений;

4) как достижение запланированных результатов.

10. К методикам оценки эффективности управленческого решения относятся:

1) косвенный метод сопоставления различных вариантов;

2) метод определения по конечным результатам;

3) метод оценок;

4) метод альтернатив.

11. Косвенный метод заключается в:

1) анализе стоимости управленческого решения путем сопоставления вариантов, разработанных и реализованных примерно в одинаковых условиях;

2) произведении полученной прибыли и доли управленческого решения в эффективности деятельности к общим затратам;

3) расчете разнищы, между полученной прибылью и долей управленческого решения в эффективности деятельности;

4) расчете разницы между отночениями прибыли при реализации при первом и втором варианте управленческого решения. 
12. Социальная эффективность управленческого решения связана с:

1) фактом достижения социальных ичелей общества в более короткие сроки меньшим числом работников с меньшими финансовыми затратами;

2) получение знаний;

3) творческом труде;

4) общении.

13. Экологическая эффективность управленческого решения характеризуется:

1) достижение нравственных иелей;

2) степенью достижения экологических иелей за более короткое время, меньшим числом работников или с меньшими финансовыми затратами;

3) достижение безопасности производства;

4) достижением технологической эффективности. 


\section{Список литературы}

1. Воронин А.В. Разработка управленческих решений: учебное пособие. - Тюмень: Тюменский индустриальный университет, $2020-123 \mathrm{c}$.

2. Ивасенко А.И. Разработка управленческих решений: учебное пособие / А.Г. Ивасенко, Я.И. Никонова, Е.Н. Плотникова. 4-е изд., стер. - М.: Кнорус, 2017. - 168 с.

3. Звягинцева О.С. Разработка управленческих решений: учебное пособие / О.С. Звягинцева, О.Н. Бабкина. - Ставрополь: Ставропольский государственный аграрный университет, 2019. - 216 с.

4. Литвак Б.Г. Разработка управленческого решения: учебник. 7-е изд. - М.: Дело АНХ, 2008. - 440 с.

5. Лукичева Л.И. Управленческие решения: учебник по специальности «Менеджмент организации» / Л.И. Лукичева, Д.Е. Егорычев; под ред. Ю.П. Анискина. - 6-е изд., стер. - М.: Омега-Л, 2011. $384 \mathrm{c.}$

6. Попов В.П. Разработка управленческих решений (многомерный подход): учебник / В.П. Попов, И.В. Крайнюченко. - Саратов: Ай Пи Эр Меда, 2019. - 136 с.

7. Строева Е.В. Разработка управленческих решений: учеб. пособ. / Е.В. Строева, Е.В. Лавова. - М.: Инфра-М, 2018. - 128 с.

8. Трофимов Л.А. Менеджмент. Методы принятия управленческих решений: учебник и практикум для СПО / Л.А. Трофимова, В.В. Трофимов. - М.: Юрайт, 2016. - 335 с. 
Учебное издание

Спорыхина Светлана Николаевна

\title{
УПРАВЛЕНЧЕСКИЕ РЕШЕНИЯ: ОСНОВНЫЕ ПОНЯТИЯ
}

\author{
Учебное пособие \\ Чебоксары, 2022 г. \\ Редактор С.Н. Спорыхина \\ Компьютерная верстка E.B. Кузнецова \\ Дизайн обложки Н.В. Фирсова
}

Подписано в печать 21.01.2022 г.

Дата выхода издания в свет 27.01.2022 г.

Формат 60×84/16. Бумага офсетная. Печать офсетная.

Гарнитура Times. Усл. печ. л. 5,3475. Заказ К-938. Тираж 500 экз.

Издательский дом «Среда»

428005, Чебоксары, Гражданская, 75, офис 12

+7 (8352) 655-731

info@phsreda.com

https://phsreda.com

Отпечатано в Студии печати «Максимум»

428005, Чебоксары, Гражданская, 75

+7 (8352) 655-047

info@maksimum21.ru

www.maksimum21.ru 